\title{
Article \\ Energy Balance Closure Problem over a Tropical Seasonal Rainforest in Xishuangbanna, Southwest China: Role of Latent Heat Flux
}

\author{
Yan Jin (D), Yue Liu, Jiahui Liu and Xiang Zhang *(D) \\ College of Ecology and Environment, Hainan University, Haikou 570228, China; jinyan8197@163.com (Y.J.); \\ I6yeah@163.com (Y.L.); jhliu666@outlook.com (J.L.) \\ * Correspondence: xiangzhang18@hainanu.edu.cn
}

Citation: Jin, Y.; Liu, Y.; Liu, J.; Zhang, $X$. Energy Balance Closure Problem over a Tropical Seasonal Rainforest in Xishuangbanna, Southwest China:

Role of Latent Heat Flux. Water 2022, 14, 395. https://doi.org/10.3390/ w14030395

Academic Editors: Ognjen Bonacci, Zhenghong Tan and Ge Sun

Received: 3 January 2022

Accepted: 25 January 2022

Published: 27 January 2022

Publisher's Note: MDPI stays neutral with regard to jurisdictional claims in published maps and institutional affiliations.

Copyright: () 2022 by the authors Licensee MDPI, Basel, Switzerland. This article is an open access article distributed under the terms and conditions of the Creative Commons Attribution (CC BY) license (https:// creativecommons.org/licenses/by/ $4.0 /)$.

\begin{abstract}
The unresolved energy-unclosed problem in micrometeorology refers to the fact that the sum of turbulent fluxes (sensible and latent heat fluxes, Hs and LE) monitored by eddy covariance (EC) methods tends to be lower than the available energy (net radiation (Rn), soil heat flux (G), and heat storage (S)). The lack of energy balance closure (EBC) increases evapotranspiration-measurement uncertainty. Using EC data from Xishuangbanna, a Southeast Asian tropical seasonal rainforest, we analyzed the energy distribution and closure based on micrometeorological features. We found that: (1) the EBC in the rainy season exceeds that in other seasons and that the seasonal moisture content, frictional wind velocity $\left(u^{*}\right)$, and LE contribute to the high seasonal variability in EBC; $(2)$ the annual closure is approximately $65 \%$, and energy non-closure is influenced by turbulence intensity and atmospheric stability. When the atmospheric state is unstable to near neutral, $\mathrm{u}^{*}$ is greatest, and EBC can reach nearly $80 \%$. (3) energy is mainly allocated to LE, and energy non-closure leads to LE underestimation, especially in the foggy-cool and hot-dry seasons. (4) Heat storage and large time-scale flux effects on EBC were excluded. The causes of energy non-closure in the tropical calm zone need further investigation.
\end{abstract}

Keywords: eddy covariance system; energy balance closure; friction velocity; atmospheric stability; latent heat flux

\section{Introduction}

Terrestrial ecosystems are critical to the regulation of carbon-water cycles and massenergy exchange both regionally and globally. As the world's most complex land ecosystem, forests, especially tropical rainforests, contain a wealth of biological resources, where the exchange of mass and energy can directly cause changes in underlying surface temperature, evapotranspiration, and productivity [1], thereby playing a crucial role in climate change [2]. The energy and mass transfer between the underlying surface and the atmosphere are accomplished mainly through turbulent exchange and diffusion in the near-surface layer [3]. Against the backdrop of global environmental change, it is essential to understand the role played by the hydrothermal exchange in tropical rainforests, and the analysis of this process will deepen our insight into the global climate system.

Currently, the eddy covariance (EC) technique is the most reliable method for directly measuring energy and material cycle in the soil-vegetation-atmosphere interface. It is widely installed in various ecosystems and has become the standard technique for studying ground-air interactions [4]. The accuracy of these data is critical for estimating terrestrial water-heat exchange, energy balance, and understanding related processes [5]. However, the system is prone to random errors due to environmental factors [6], resulting in the difference between monitoring data and the actual fluxes, which give rise to one of micrometeorology's long-standing problems. Moreover, there is usually an incongruity between the sum of the sensible and latent heat fluxes and the available energy in most 
EC monitoring systems, resulting in the non-closure of the surface energy balance [7]. The emergence of the energy balance closure (EBC) problem has raised questions about the accuracy and reliability of EC measurements. Therefore, the lack of EBC is an important indicator when estimating terrestrial energy, water, and heat balances using the EC method. Since Foken and Oncley identified this problem in 1995 [8], extensive related research has been conducted on the EBC problem.

Multiple explanations for energy non-closure have been proposed in previous studies. Thomas and Stoy et al. $[9,10]$ reported that larger time-scale turbulent exchange processes arising in heterogeneous landscapes significantly impact energy imbalance, causing the loss of the low-frequency part of the turbulence spectra. Leuning et al. [11] noted that an improper instrument setup can cause the loss of high-frequency covariance. Some scholars have emphasized that incorrect calculation of energy storage between the surface and atmosphere and heat storage have been ignored or assumed to be negligible in most studies $[12,13]$. Despite the amount of research on this problem, the EBC is still a prominent issue in the study of surface-atmosphere interactions. Yet the reasons for energy non-closure are still not completely clear, and the explanations so far are not perfect.

Numerous studies have reported on energy allocation and closure in tropical rainforests, temperate forests, grasslands, and agricultural lands, but few have been conducted in tropical seasonal rainforests [14-16]. Tropical seasonal rainforests are located in the famous tropical calm zone, and the geographical location has created unique climate characteristics, making them different from conventional tropical rainforests. In the past, related studies mainly focused on carbon balance, radiation balance, and water-heat fluxes, and research devoted to the surface EBC remains underrepresented. In this study, long-term observation data of tropical seasonal rainforests were used to study the problem. The data were selected from a newly installed EC system in Bubang Village, Mengla County, Xishuangbanna, China.

In this particular ecosystem, we were interested in whether the energy closure condition was different from that of conventional rainforest, what degree of closure could be achieved, and which factors affected EBC. Our aims were to compare and analyze the micrometeorological parameters and factors influencing EBC. Considering the importance of mass and energy exchange between terrestrial ecosystems and the atmosphere and the absence of such studies in Xishuangbanna, this study analyzed the seasonal dynamics of EBC and explained the seasonal differences. In addition, the causes of the energy imbalance were quantified and, based on the climate and many previous studies on other ecosystems, a series of hypotheses were made regarding surface EBC and hydrothermal characteristics: (1) The forest canopy of the study region is dense, and the intensity of energy exchange is not large. Therefore, coupled with the insulation effect of dense fog on the underlying surface and the heat generated by the decomposition of a large number of fallen leaves during the hot-dry season, it was expected that a considerable amount of energy would be stored between the canopy and the underlying surface and that this heat storage would significantly increase the EBC. (2) The region is known as a calm zone, and the average wind velocity in the observed year was $0.9 \mathrm{~m} \cdot \mathrm{s}^{-1}$. Monitoring data from the EC system may not accurately reflect the actual conditions. Then, with the increase in friction wind velocity $\left(u^{*}\right)$, the mass and energy exchange should be improved, and an obvious positive correlation between $\mathrm{u}^{*}$ and EBC would be obtained. (3) Numerous studies have shown that the conventional average output time cannot capture low-frequency flux data, causing energy non-closure. Extending the time scale to daily, weekly, and yearly periods can effectively reduce the low-frequency loss and improve the EBC. (4) The low wind velocity and insufficient turbulence development mean that the monitoring data were likely to be underestimated and using the degree of EBC to estimate the turbulent fluxes would increase the accuracy of the values. 


\section{Materials and Methods}

\subsection{Study Site Conditions}

Xishuangbanna is located in the northern part of tropical Southeast Asia. Due to its unique climate pattern and phenological characteristics, it has nurtured a tropical seasonal rainforest that differs from typical tropical rainforests. This has attracted the attention of many researchers. Since 2002, ChinaFLUX has successively installed EC towers in Xishuangbanna. A newly installed flux monitoring system $\left(21^{\circ} 36^{\prime} 50^{\prime \prime} \mathrm{N}, 101^{\circ} 34^{\prime} 36^{\prime \prime} \mathrm{E}\right)$ in a 20-hectare plot in Bubang Village, Mengla County, was selected to conduct long-term continuous dynamic monitoring of flux and climate (Figure 1). The region has a tropical monsoon climate and is affected by the southwest monsoon throughout the year, with strong seasonality [17]. Its natural environment has a mean temperature of $21.7^{\circ} \mathrm{C}$ with significant variability over the year, and the precipitation distribution is also extremely uneven. In the dry season (from November to April), under the influence of the subtropical continental air mass, there is fog and less rain. There are also obvious variations in the dry season climate, which can be further divided into foggy-cool seasons (November-February) and hot-dry seasons (March-April). During the hot-dry seasons, the daytime temperature is higher (the highest temperature can reach $38^{\circ} \mathrm{C}$ ), and the radiation fog disperses easily. The foggy-cool season is characterized by low temperature (average temperature of $17.5^{\circ} \mathrm{C}$ ), and dense radiation fog is present most of the day [18]. Monsoons are usually associated with southwesterly winds and advection of moist marine air masses from the Indian Ocean. These conditions are typical of the rainy season, which occurs from May to October. High temperatures and rainfall characterize the rainy season, and rainfall accounts for $87 \%$ of the annual precipitation $(1493 \mathrm{~mm})$. The climatic condition accounts for the special phenological phenomenon of the tropical seasonal rainforest, i.e., sprouting new leaves in the rainy season and concentrated defoliation in the dry season [19].
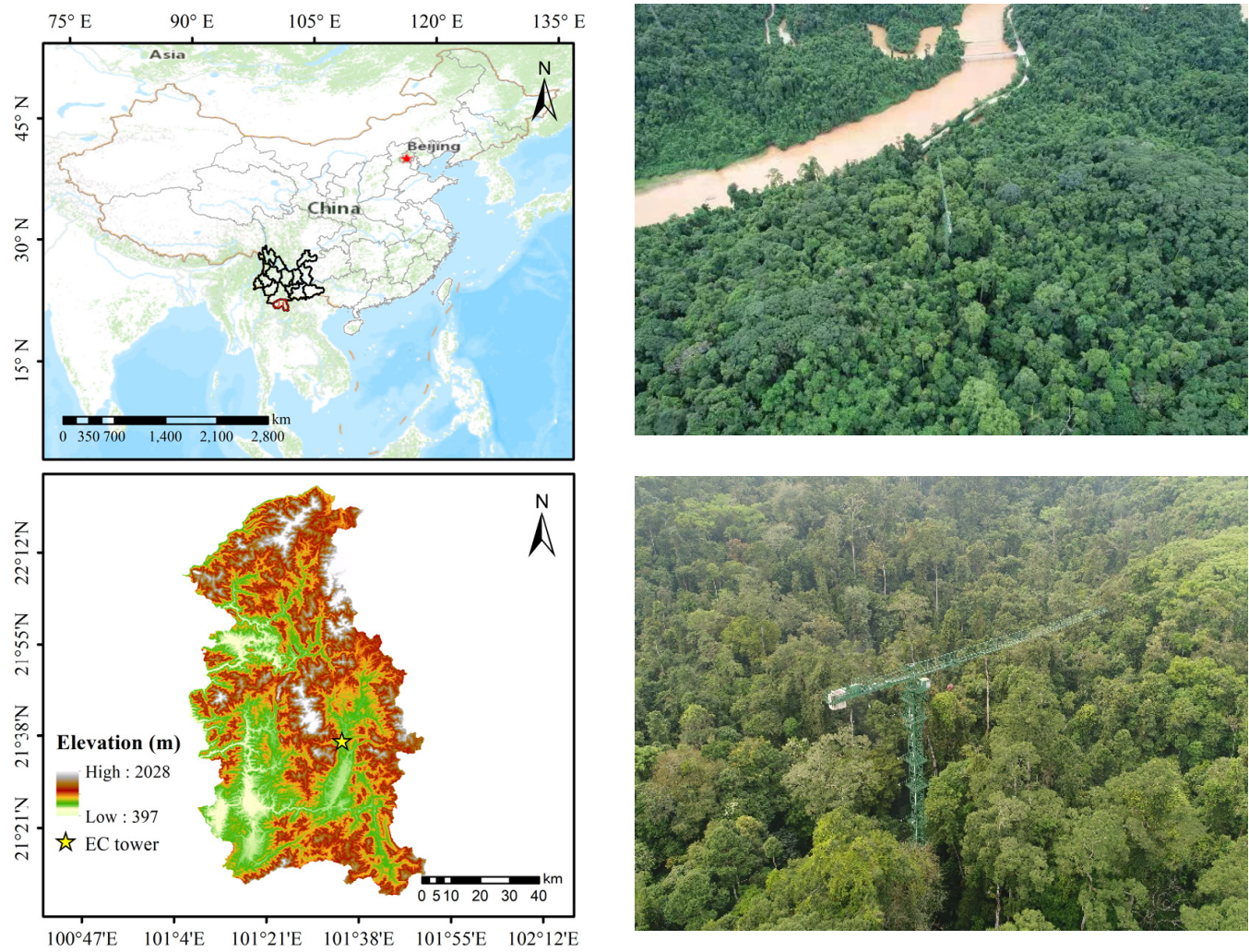

Figure 1. Geographical location and elevation information of the EC flux tower in Bubang Village, Mengla County, Xishuangbanna (left); images in study region (right). 
There are two types of tropical rainforests in Xishuangbanna: the mountain rainforest at high altitudes (above $770 \mathrm{~m}$ ) and the seasonal rainforest located in valleys and low hills (below $770 \mathrm{~m}$ ). The forest tower crane observation system was set up in a mountain valley at $653.4 \mathrm{~m}$. This rainforest has attracted much attention because of the presence of Parashorea chinensis Wang Hsie of the Dipterocarpaceae, which has an upper canopy as high as 50-60 m. In addition, the canopy height of other trees is generally $30-35 \mathrm{~m}$. The main species are Garcinia cowa, Pometia tomentosa, Sloanea tomentosa, Pittosporopsis kerrii, and Mezzettiopsis creaghii [20]. This region is known as a calm zone [21], where turbulence is not fully developed, and the phenomenon of insufficient turbulence exchange is aggravated by the shielding effect of dense fog and forest canopy. Above the canopy, an open-path eddy monitoring system and a conventional weather monitoring system were installed on the tower crane with a maximum working height of $81 \mathrm{~m}$ to monitor related indicators.

\subsection{Monitoring Instrument Setup and Data Processing}

An open-path eddy covariance system (OPEC) was installed at $68.1 \mathrm{~m}$ on the tower and provided long-term, almost continuous half-hourly averaged monitoring data of turbulence and energy fluxes (sensible heat (Hs), latent heat (LE), and carbon dioxide flux). An infrared gas analyzer (Li-7500, Li-Cor Inc., Lincoln, NE, USA) and a three-dimensional sonic anemometer (CSAT3, Campbell Scientific Inc., Logan, UT, USA) were also installed. These data from the OPEC were sampled at $10 \mathrm{~Hz}$ using a data acquisition system (CR3000, Campbell Scientific Inc., Logan, UT, USA).

A net radiometer CNR4 (Kipp \& Zonen, Delft, The Netherlands) was installed at $77.7 \mathrm{~m}$ to monitor radiation fluxes. Monitoring equipment for air temperature and humidity (HMP45C, Vaisala, Helsinki, Finland), wind velocity (A100R, Vector Instruments, Denbighshire, UK), and photosynthetically active radiation (LQS70-10, Apogee, Logan, UT, USA) were installed in five locations on the tower $(1.4 \mathrm{~m}, 62.1 \mathrm{~m}, 68.1 \mathrm{~m}, 77.7 \mathrm{~m}, 81.6 \mathrm{~m})$. Soil temperature and moisture were measured at seven levels located at approximately 5 , $10,20,40,60,80$, and $100 \mathrm{~cm}$ below the ground surface. Soil heat flux data were measured using a heat flux plate (HFP01, HukseFlux, Delft, The Netherlands), which was placed $5 \mathrm{~cm}$ below the surface, and the sampling frequency of meteorological data was set at $0.5 \mathrm{~Hz}$.

Continuous observational data from November 2014 to August 2016 were chosen for the analysis. To eliminate horizontal and vertical advection terms, 3D coordinate rotation was performed on $30 \mathrm{~min}$ flux data according to Aubinet and Grelle et al. [22], and the $\mathrm{LE}, \mathrm{Hs}$, and $\mathrm{CO}_{2}$ fluxes were calculated using the covariance of the rotational vertical wind velocity with water vapor concentration, air temperature, and $\mathrm{CO}_{2}$ concentration. In addition, the OPEC is susceptible to climate change, so the data were screened using the ChinaFLUX standard. Conventional meteorological data were less affected by weather changes, so only abnormal values of radiation values and soil heat fluxes were eliminated. The interpolation method for missing data depends on the length of the gap. If the data intervals were less than 4 (i.e., 2 h), the linear interpolation method was adopted; otherwise, the monthly average value at the same time was used as a replacement $[23,24]$.

\subsection{Energy Balance Closure Problem}

In the ecosystem, the first law of thermodynamics shows that energy neither comes into being nor disappears, and only the transformation of form occurs. According to Campos et al. [15], the complete available energy is composed of net radiation (Rn), soil heat flux $(\mathrm{G})$, and heat storage $(\mathrm{S})$ in the soil, air below the tower, and biomass. Under an ideal condition in which the monitoring system is without errors and losses, the turbulent flux (LE, Hs) and the available energy satisfy the energy balance relationship:

$$
\mathrm{Rn}-\mathrm{G}-\mathrm{S}-\mathrm{Q}=\mathrm{LE}+\mathrm{Hs}
$$

where $Q$ mainly refers to the additional energy used for photosynthesis and respiration, which was neglected in this study because of its small value [25]. S is the sum of the heat storage; some researchers ignore it because heat storage makes a negligible contribution to 
EBC [11], which is generally found in the ecosystem with a short canopy and low vegetation coverage, such as grassland and farmland ecosystems [26,27]. However, previous studies have shown that energy cannot be completely closed. McCaughey [28] concluded that heat storage should be considered in ecosystems with a high canopy (plant height greater than $8 \mathrm{~m}$ ), so the contribution of heat storage to EBC was explored in this study. The heat storage can be written as:

$$
\mathrm{S}=\mathrm{Ss}+\mathrm{Sa}+\mathrm{Se}+\mathrm{Sc}+\mathrm{St}
$$

where $S$ is the total heat storage, including the soil heat storage (Ss) between the heat flux plate and the soil surface, the sensible heat (Sa) and latent heat storage (Se) of the air below the canopy, the canopy heat storage in biomass $(\mathrm{Sc})$, and the heat storage of the tree branches (St). Because of the lack of stalk-monitoring data, St was ignored in the calculation. The remaining heat storage was calculated according to the method of Blanken et al. [29-31].

Based on the experimental observations, the energy of forest ecosystems is always unclosed, and, therefore, factors other than heat storage may be responsible for the lack of surface EBC. Thus, the energy residual (Res) can be expressed as:

$$
\text { Res }=\mathrm{Rn}-\mathrm{G}-\mathrm{LE}-\mathrm{Hs}-\mathrm{S}
$$

In this study, two statistical methods were used to evaluate EBC comprehensively. The first method was linear regression, where linear regression coefficients (slope and intercept) between turbulent fluxes and available energy were derived in ordinary least squares (OLS) relations to determine the EBC. Ideally, a straight line with a slope of 1 and through the origin can be obtained. Another method was to calculate the long-term averaged energy balance ratio (EBR) [32,33], which is the ratio of the monthly cumulative sums of turbulent flux and available energy per half-hour data; the best result is achieved when the EBR is one.

$$
\mathrm{EBR}=\frac{\sum(\mathrm{LE}+\mathrm{Hs})}{\sum(\mathrm{Rn}-\mathrm{G}-\mathrm{S})}
$$

\subsection{Atmospheric Stability Parameter}

Eddy fluxes vary with weather conditions, and environmental changes may be an influential factor in EBC. Therefore, we chose conventional and representative variables and evaluated their relationships with the EBC. The turbulence intensity is closely related to the atmospheric stability, and $\mathrm{u}^{*}$ determines the magnitude of the atmospheric stability. It can be inferred that the EBR is a function of $\mathrm{u}^{*}$ and atmospheric stability [22]. The Monin-Obukhov atmospheric stability parameter (乙), which comprehensively considers the mechanisms of turbulence generation, is widely used to describe the stability of the atmospheric boundary layer.

$$
\zeta=\frac{\mathrm{z}-\mathrm{d}}{\mathrm{L}}
$$

where $\mathrm{z}$ is the observed height $(\mathrm{m})$, and $\mathrm{d}$ is the zero-plane displacement height $(\mathrm{m})$ $(\mathrm{d}=2 \mathrm{~h} / 3$ for the underlying surface with dense vegetation [34]). The Obukhov length (L), as the main determinant of the characterized atmospheric stability, can account for the contribution of $u^{*}$ and thermal turbulence [10]:

$$
\mathrm{L}=\frac{-\rho \mathrm{C}_{\mathrm{p}} \mathrm{u}^{* 3} \mathrm{~T}_{\mathrm{a}}}{\mathrm{kgH}_{\mathrm{s}}}
$$

where $\rho$ is the density of air $\left(\mathrm{kg} \cdot \mathrm{m}^{-3}\right), \mathrm{C}_{\mathrm{p}}$ is the specific heat of air at constant pressure $\left(1004 \mathrm{~J} \cdot \mathrm{kg}^{-1} \cdot \mathrm{k}^{-1}\right), \mathrm{k}$ is Karman's constant $(\mathrm{k}=0.41$ [35]), $\mathrm{g}$ is the acceleration due to gravity $\left(\mathrm{m} \cdot \mathrm{s}^{-2}\right)$, and Ta is the air temperature $(\mathrm{k})$. Referring to Sanchez et al. [36], EBC was analyzed as a function of $\zeta$ for the site, dividing the data into five stability classes: very unstable 
$(\zeta<-1)$, unstable $(-1<\zeta<-0.01)$, neutral $(-0.01<\zeta<0.01)$, stable $(0.01<\zeta<1)$, and very stable $(\zeta>1)$.

To illustrate the contribution of environmental factors to EBC, the potential relationships between the relevant parameters (i.e., OLSs, EBR, Res, Bowen ratio $(\beta)$ ) and $\zeta$ or $\mathrm{u}^{*}$ were explored. Taking $\zeta$ and $\mathrm{u}^{*}$ as criteria, the relevant parameters were arranged in order from smallest to largest, and then the half-hourly monitoring data were divided into 10 categories. The slope was obtained by linear fitting for the turbulent flux and available energy within each decile, and the EBR, $\beta$, and Res in each decile were calculated. It is noted here that because the eddy flux data are highly fluctuating and often have outliers, $u^{*}$, $\zeta, E B R$, and Res used the median of each decile, and the average of $\beta$ was used to analyze the variation pattern of EBC with dynamic turbulence and atmospheric stability.

\subsection{Leaf Area Index}

The surplus or deficit of water content affects the length of leaf life, and the leaf area index data represent the seasonal variation of the vegetation in response to precipitation. Based on the Beer-Lambert extinction law, the leaf area index (LAI) of the canopy was calculated using photosynthetically active radiation (PAR) data from above and below the canopy to obtain leaf phenology dynamics. Because of the large inter-daily variability of the solar altitude angle, this study only used the data around noon to inversion, since theoretical analysis showed that the solar altitude angle varied by less than $10 \%$ during this period, the relationship can be expressed as follows [37,38]:

$$
\mathrm{LAI}=-\frac{1}{\mathrm{~K}} \ln \frac{\mathrm{I}}{\mathrm{I}_{0}}
$$

where I represents the PAR reaching the understory $(1.4 \mathrm{~m}), \mathrm{I}_{0}$ is the photosynthetically active radiation above the forest $(77.7 \mathrm{~m})$, and $\mathrm{K}$ is the extinction coefficient, which was taken as 0.75 in this study.

\section{Results}

\subsection{Meteorological Situations in the Study Area}

Figure 2 illustrates the intra-annual temporal average variation of daily net radiation $(\mathrm{Rn})$, temperature (Ta), soil water content (SWC), water vapor pressure deficit (VPD), and leaf area index (LAI). Overall, the solar radiation in the Xishuangbanna tropical seasonal rainforest exhibited obvious seasonal fluctuations (Figure 2a). The Rn was maintained between 3 and $25 \mathrm{MJ} \cdot \mathrm{m}^{-2} \cdot \mathrm{d}^{-1}$ throughout the year, and the radiation values were concentrated in the foggy-cool and hot-dry seasons. There were significant daily fluctuations during the rainy season due to frequent cloudy weather, and the radiation values were scattered. The maximum Rn value occurred at the end of the hot-dry season ( $\mathrm{Rn}$ reached 18.32 $\left.\mathrm{MJ} \cdot \mathrm{m}^{-2} \cdot \mathrm{d}^{-1}\right)$, the Rn decreased overall in the rainy season due to cloudiness and albedo (on average, $11.79 \mathrm{MJ} \cdot \mathrm{m}^{-2} \cdot \mathrm{d}^{-1}$ ), the foggy-cool season was foggy and, together with the influence of solar-earth relations, the $\mathrm{Rn}$ also remained low. The Ta showed a distinct seasonal pattern with lower temperature values during the foggy-cool season and higher temperatures in the hot-dry and rainy seasons (Figure $2 \mathrm{~b}$ ). The average Ta varied from $9.57^{\circ} \mathrm{C}$ (January 25) to $26.26^{\circ} \mathrm{C}$ (May 11). There was a large diurnal range between the hot-dry and foggy-cool seasons. The Ta increased obviously in the hot-dry season, was relatively stable in the rainy season, and fluctuated slightly around $25^{\circ} \mathrm{C}$.

The annual variation in the SWC is presented in Figure 2c. As the temperature rose and reduced precipitation combined with evaporation of water from the soil and uptake by plant growth, SWC in the three soil layers declined gradually to as low as $0.09 \mathrm{~m}^{3} \cdot \mathrm{m}^{-3}$, $0.21 \mathrm{~m}^{3} \cdot \mathrm{m}^{-3}, 0.27 \mathrm{~m}^{3} \cdot \mathrm{m}^{-3}$ during the hot-dry seasons, respectively. However, during the rainy season, it remained at high values, as the soil water was recharged by frequent rainfall. It is important to highlight that the deeper the soil, the higher the water content. This may be related to geography. The tower crane observation system was set up in a low-lying valley, a water catchment area, and $180 \mathrm{~m}$ east of the tower crane is the Nanla River, a 
tributary of the Lancang River. Thus, the replenishment of groundwater was adequate, explaining the higher water content of the deeper soil.

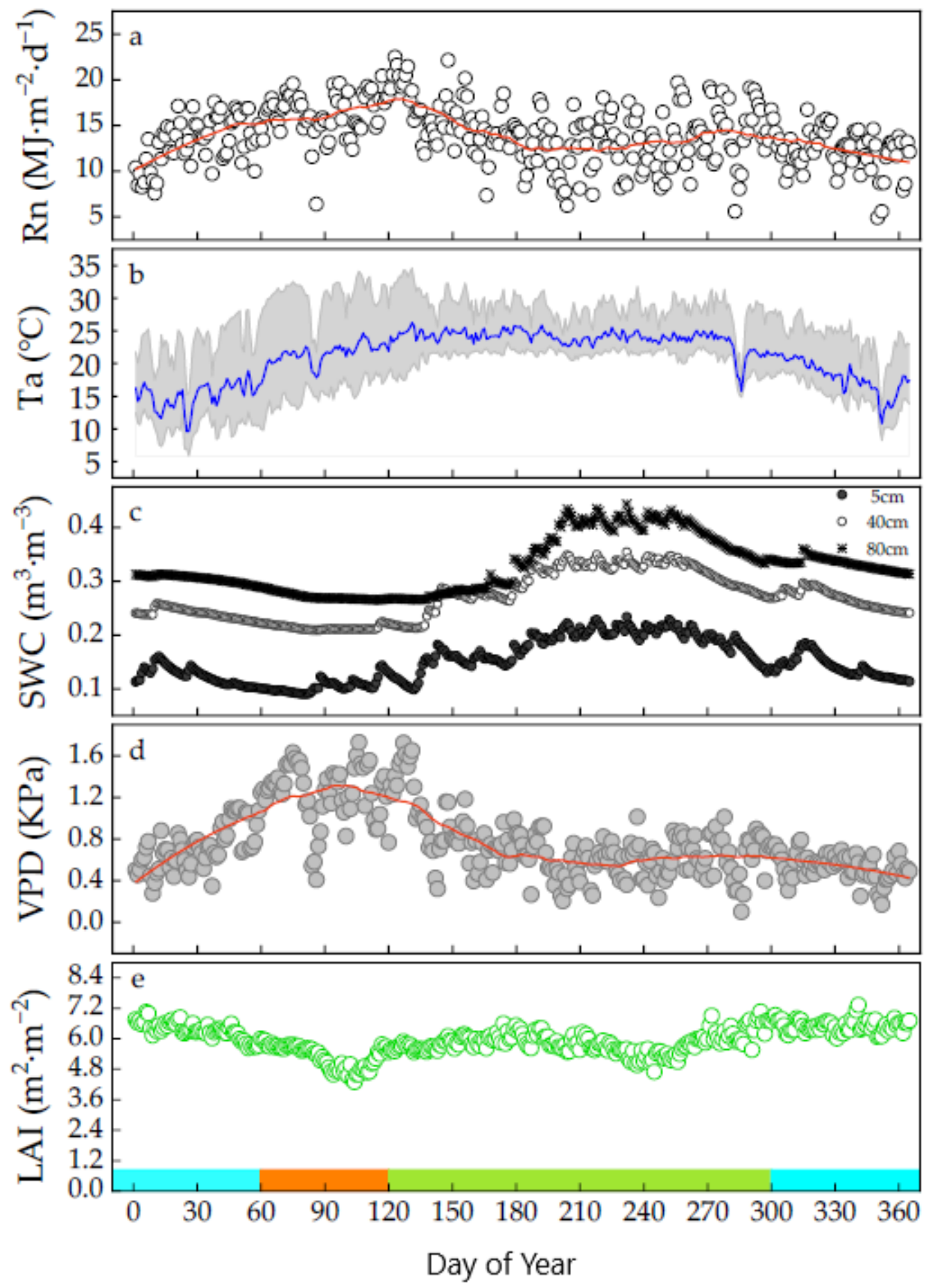

Figure 2. Meteorological conditions during the study period, (a) net radiation $\mathrm{Rn}$; (b) air temperature $\mathrm{Ta}$, shaded area is the difference between the maximum and minimum values; (c) soil water content SWC; (d) vapor pressure deficit VPD; (e) leaf area index LAI, where lake blue indicates the foggy-cool season, orange indicates the hot-dry season, and green is the rainy season.

Notably, VPD and SWC displayed the opposite strong seasonal variation (Figure 2d). The highest VPD values were observed in the hot-dry season, and the minimum VPD value occurred during the foggy-cool season in December. This is expected because the higher air temperature during the hot-dry season can hold more water molecules, and the saturation 
water vapor pressure is high, while the rainfall deficit leads to actual water vapor pressure being small. Conversely, the lowest values occurred during the foggy-cool season because the temperature was low, and the dense fog maintained the actual water vapor pressure.

The climatic characteristics of the study area were closely related to the seasonal rainfall variation. The SWC variability showed seasonality consistent with the seasonal rainfall cycle, whereas the VPD variability was opposite to the seasonal changes in rainfall. The leaves adjusted their life strategy according to water limitation, and the LAI (Figure 2e) was used in this study to reflect the vegetation response to rainfall. Unsurprisingly, the seasonal variation in vegetation is in accordance with the seasonal variability of rainfall. Leaves began to wither slowly at the beginning of the year, and during the hot-dry season, plants entered a period of concentrated withering due to the desiccation tolerance mechanism in response to water deficit, with LAI reaching a minimum value $\left(4.3 \mathrm{~m}^{2} \cdot \mathrm{m}^{-2}\right)$ at the end of the hot-dry season. On the other hand, with the arrival of the rainy season, the plants recovered and grew rapidly, returning to almost normal levels in mid-June. The leaves then continued to grow until leaf-fall in the next dry season.

\subsection{Annual and Diurnal Dynamics of Frictional Velocity and Atmospheric Stability}

Figure $3 a, b$ shows the percentages of different categories of atmospheric stability $\zeta$ and frictional velocity $\mathrm{u}^{*}$. In the study of the effect of $\mathrm{u}^{*}$ on EBC, it was found that a turning point occurred at $0.325 \mathrm{~m} \cdot \mathrm{s}^{-1}$ (as demonstrated in Section 3.4). Therefore, $\mathrm{u}^{*}$ was divided into three categories using $0.2 \mathrm{~m} \cdot \mathrm{s}^{-1}$ (the usual data screening standard) and $0.325 \mathrm{~m} \cdot \mathrm{s}^{-1}$ as the boundary. During the rainy season, the proportion of the stable atmospheres increased and peaked in July $(\approx 40 \%)$. The proportion of very unstable atmospheres decreased and then increased from the beginning of the hot-dry season to the end of the rainy season. However, during this period, $\mathrm{u}^{*}$ changed in the opposite direction, and the frequency of large $\mathrm{u}^{*}$ increased, with $80 \%$ of $\mathrm{u}^{*}$ greater than 0.2 in June. The proportion of $\zeta$ and $\mathrm{u}^{*}$ in each category remained almost constant during the foggy-cool season.
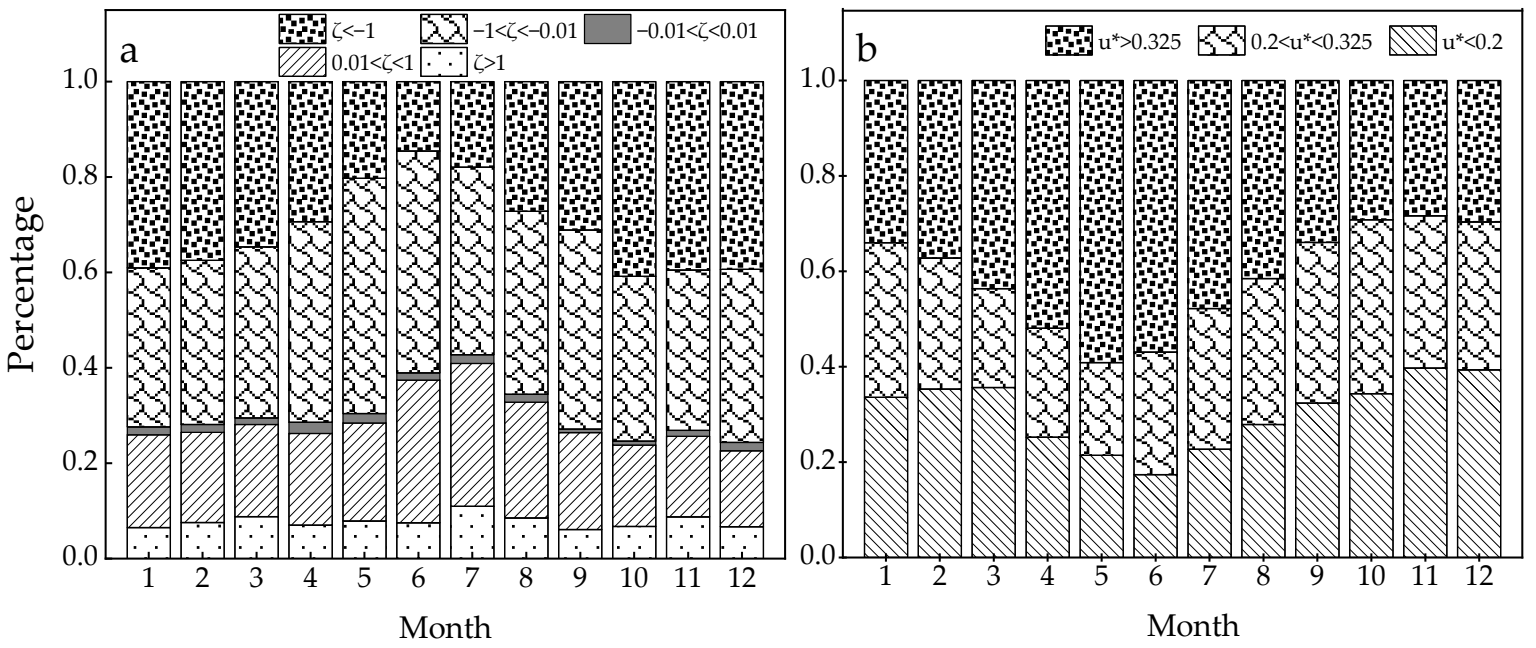

Figure 3. Cumulative frequency stack plots for the study period, (a) atmospheric stability, classified into the following five categories: very unstable $(\zeta<-1)$, unstable $(-1<\zeta<-0.01)$, neutral $(-0.01<\zeta<0.01)$, stable $(0.01<\zeta<1)$, and very stable $(\zeta>1)$; (b) frictional velocity.

The daily average variations of $\mathbf{u}^{*}$ and $\zeta$ are shown in Figure $4 \mathrm{a}, \mathrm{c}$. The two curves show an inverse trend. It can be seen that $\mathrm{u}^{*}$ was almost less than $0.2 \mathrm{~m} \cdot \mathrm{s}^{-1}$ from 20:00 to 08:00 (local time) of the next day, and turbulent exchange was very weak at night. The $\mathrm{u}^{*}$ increased rapidly after sunrise, reaching a peak of $0.42 \mathrm{~m} \cdot \mathrm{s}^{-1}$ at $14: 30$. The atmosphere was stable from 18:00 to 08:00 on the next day. As the solar altitude angle increased, the atmosphere reached a highly unstable state at noon $(\zeta=-0.77)$ due to thermal convection. The overall annual variation of $\mathrm{u}^{*}$ and $\zeta$ (Figure $4 \mathrm{~b}, \mathrm{~d}$ ) was consistent with the cumulative frequency stack plot (Figure 3 ). Because of the small $u^{*}$ and the stability of the atmospheric 
section at night, the large measurement error of turbulent fluxes was not conducive to the assessment of EBC. Thus, the annual variation was expressed as daytime data to assist the analysis of the energy closure characteristics. The annual cycle of $\mathrm{u}^{*}$ gradually increased during the hot-dry season, reached a maximum at the beginning of the rainy season, and then slowly decreased and returned to its initial level in the foggy-cool season (Figure $4 \mathrm{~b}$ ). The annual cycle of $\zeta$ calculated with daytime data was almost in an unstable state (Figure $4 \mathrm{~d}$ ), especially during the foggy-cool and hot-dry seasons. Entering the rainy season, the $\zeta$ developed toward neutrality, and the distribution of data points was concentrated at -0.5 to 0 , with a small stability fraction.

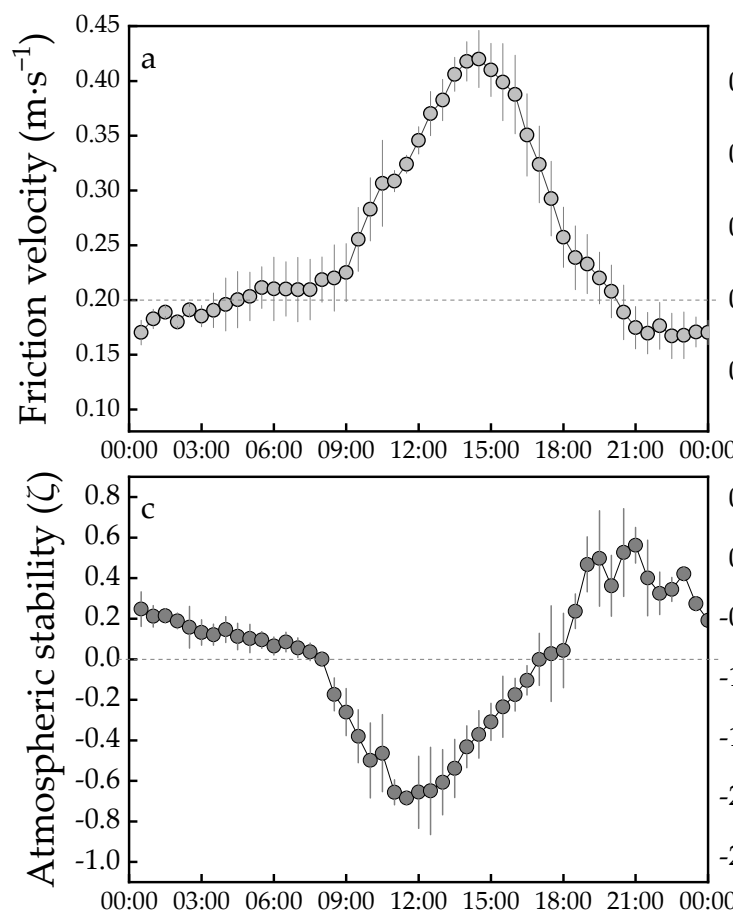

Hour of Day
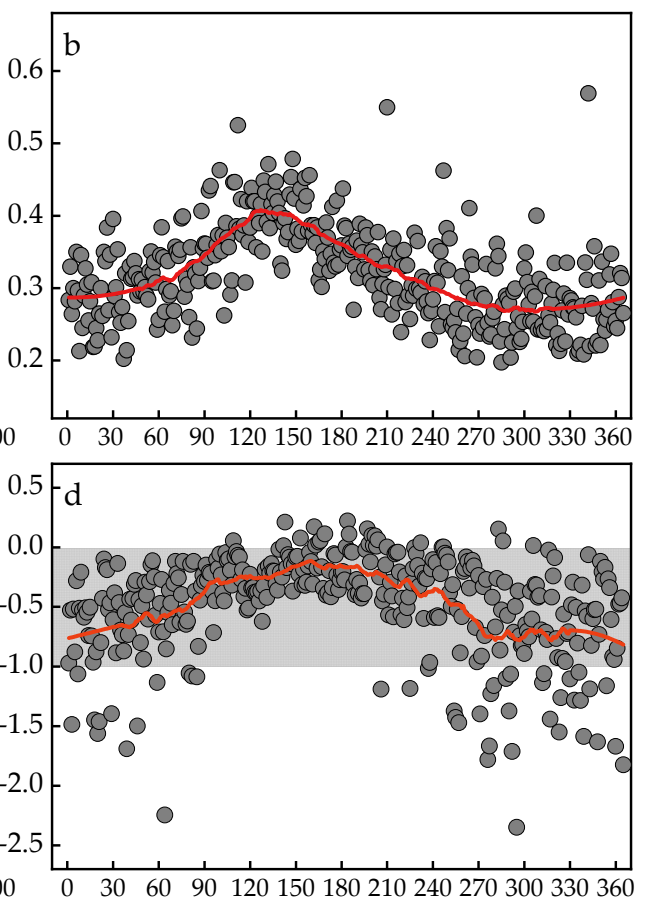

Day of Year

Figure 4. Median daily and annual cycles of frictional velocity $(\mathbf{a}, \mathbf{b})$, atmospheric stability (c,d), and error bars indicate standard errors. Among them, the annual variation diagrams $(\mathbf{b}, \mathbf{d})$ only represent daytime conditions, where the shaded part shows the range of instability.

\subsection{Overall Energy Balance Closure (EBC) in the Tropical Seasonal Rainforest}

There are obvious seasonal differences in the tropical seasonal rainforests of Xishuangbanna, and the EBC is also affected by them. Because it is a calm zone, the wind velocity is relatively small compared to other places, especially since the turbulent exchange is weak at night (Figure 4a). Therefore, continuous daytime observation data (total radiation $>10 \mathrm{~W} \cdot \mathrm{m}^{-2}$ ) were chosen to analyze the EBC in this study [39]. The surface EBC varied slightly depending on the method used to calculate the degree of closing. In this study, two methods (OLSs and EBR) were used to analyze the EBC in different seasons (Figures 5 and 6). When EBC was calculated by using OLSs, considering the heat storage below the canopy, it was found that the energy was not only unclosed but also partially residual, with a slope less than 1 in all cases. Two linear regression results with intercept (red line) and forced through the origin (green line) are given during the analysis. The results were obtained by integrating all half-hour data, where the slope ranged from 0.526 (foggy-cool season) to 0.645 (rainy season), where the slope for the whole year was 0.593 . The intercept ranged from $8.654 \mathrm{~W} \cdot \mathrm{m}^{-2}$ (foggy-cool season) to $27.90 \mathrm{~W} \cdot \mathrm{m}^{-2}$ (rainy season). Considering that the ideal condition of EBC is that the linear regression line of the available energy and turbulent flux passes through the origin with a slope of 1 , and because the intercept was relatively small in this study, we chose to force the intercept to 
zero. After eliminating the intercept, the annual EBC reached 0.633 , and the coefficient of determination $\left(\mathrm{R}^{2}\right)$ was 0.748 (Figure $5 \mathrm{a}$ ). Because the environmental conditions gradually changed in each season, the EBC also showed significant seasonal differences, the slope varied between 0.545 and 0.704 , and the coefficients of determination were all above 0.75 , which indicated a suitable fitting effect. The slope of the hot-dry season (Figure $5 b$ ) was intermediate (0.604), the rainy season (Figure 5c) was 0.704, which was the highest among the three seasons, and the foggy-cool season (Figure 5d) had a weak turbulent exchange and poor closure. A two-dimensional kernel density analysis of the data points for the available energy and turbulent fluxes shows that the data points are concentrated in the range of $200 \mathrm{~W} \cdot \mathrm{m}^{-2}$ horizontal and vertical coordinates, and the subsequent data are relatively dispersed. Using $200 \mathrm{~W} \cdot \mathrm{m}^{-2}$ as the threshold, regression analysis was performed separately for data points less than $200 \mathrm{~W} \cdot \mathrm{m}^{-2}$ and greater than $200 \mathrm{~W} \cdot \mathrm{m}^{-2}$, and it was found that the latter had a higher slope. The smaller fluxes pull down the energy closure level, indicating that insufficient turbulence development and incomplete energy exchange may be the factors influencing energy non-closure.
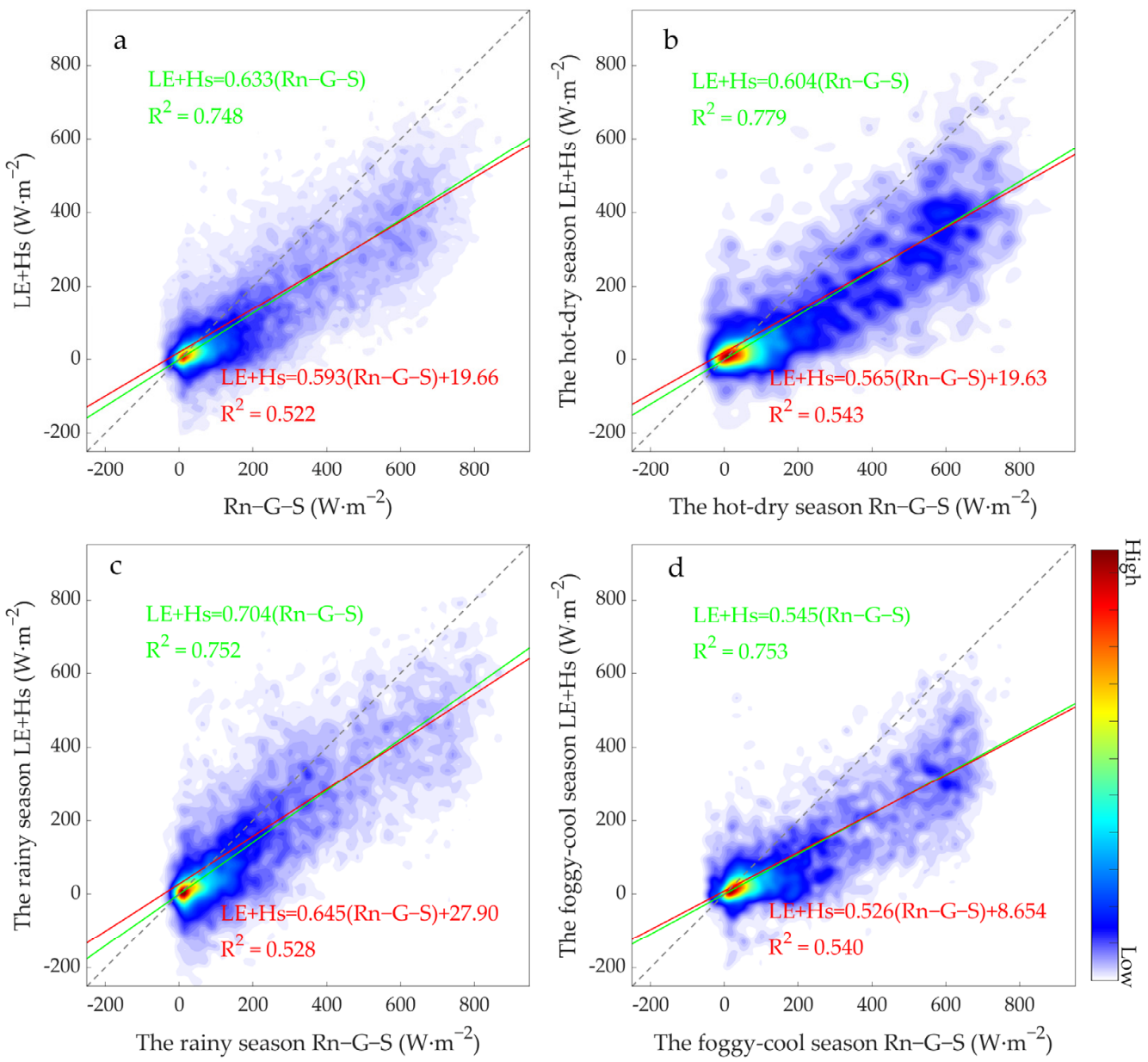

Figure 5. Two-dimensional kernel density distribution and linear regression plots of turbulent flux $(\mathrm{LE}+\mathrm{Hs})$ and available energy $(\mathrm{Rn}-\mathrm{G}-\mathrm{S})$ in different seasons: (a) throughout the year, (b) the hot-dry season, (c) the rainy season, (d) the foggy-cool season. The color bar of the kernel density distribution represented the degree of aggregation of data points, with the colors ranging from white to red corresponding to the density of data points from low to high progressively. The diagram shows the gray-dashed line past the origin with a slope of 1 . The solid green line is obtained by forcing the intercept to 0 , and the solid red line has both slope and intercept. 


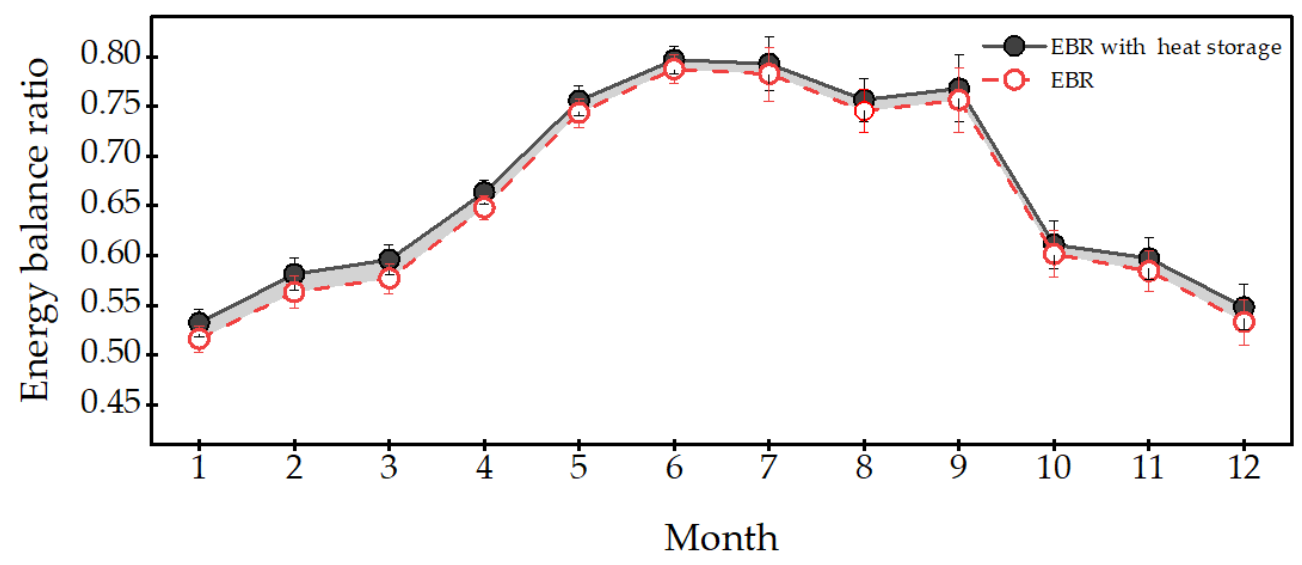

Figure 6. Average annual variation of energy balance ratio, where filled dots and solid lines indicate heat storage is considered, hollow circles and dashed lines indicate EBR without heat storage, and error bars indicate standard errors.

The energy balance ratio (EBR) can also reflect the degree of EBC; when using the EBR method to observe EBC, the values varied from 0.53 to 0.80 throughout the year. Figure 6 shows the annual cycle of the EBR, which was obtained by the sum of the sensible and latent heat versus the monthly total available energy. The dashed line with circles in the figure does not include the heat flux terms $\mathrm{S}$, and the solid line with dots represents the complete surface EBC equation. During this period, the minimum and maximum values of EBR occurred in January and June, respectively. The results show that ignoring heat storage is not the main reason for energy non-closure in tropical seasonal rainforests. Even when heat storage was considered, the EBR only increased by $0.9 \sim 1.9 \%$. The inter-seasonal variation in EBR was significant, and similar results were reproduced in terms of the linear regression, with higher values during the rainy season and lower values in the foggy-cool season (0.565); the closure increased significantly during the hot-dry season and reached 0.76 at the end of May. The rainy season (0.747) remained at a relatively stable level, and all minor variations occurred above 0.70, except for October, with the best EBC observed in June. The average annual EBR was 0.67. All heat storage was considered, and there was still an imbalance of $33 \%$.

\subsection{Variations of EBC under Different Atmospheric Conditions}

\subsubsection{Relationship between EBC and Frictional Velocity}

The critical role of turbulence intensity in the EBC can be observed by the relationship between the EBC, Res, and $\mathrm{u}^{*}$ (Figure 7a,b). The relationship between EBC and $\mathrm{u}^{*}$ was evaluated by dividing the half-hourly data into 10 unified atomic mass $u^{*}$ groups in deciles and then calculating the linear regression slope and EBR for each group separately. Friction velocity tends to be small at night, resulting in turbulent fluxes being underestimated to some extent; therefore, it is difficult to determine the actual degree of EBC at night, so the study results were exhibited only during the daytime. Figure 7a shows the variation of EBR and OLSs with $\mathrm{u}^{*}$, and the trend is the same for both. When $\mathrm{u}^{*}$ is very small, the surface EBC is approximately 0.5 , and a greater EBC occurs under the condition of higher $u^{*}$. The curve was divided into two parts with $0.32 \mathrm{~m} \cdot \mathrm{s}^{-1}$, for $\mathrm{u}^{*}$ values below $0.32 \mathrm{~m} \cdot \mathrm{s}^{-1}$, EBC improved in the study area as $u^{*}$ values increased by approximately $15 \%-20 \%$. When $u^{*}$ was higher than $0.32 \mathrm{~m} \cdot \mathrm{s}^{-1}$, the EBC continued to increase slowly, and it reached its peak until the maximum $\mathrm{u}^{*}$ values were approached. This indicates that $\mathrm{u}^{*}$ determines the EBC in this region, but it is not a unique influencing factor. When $\mathrm{u}^{*}$ increases to a certain value, the EBC is no longer affected by it. 


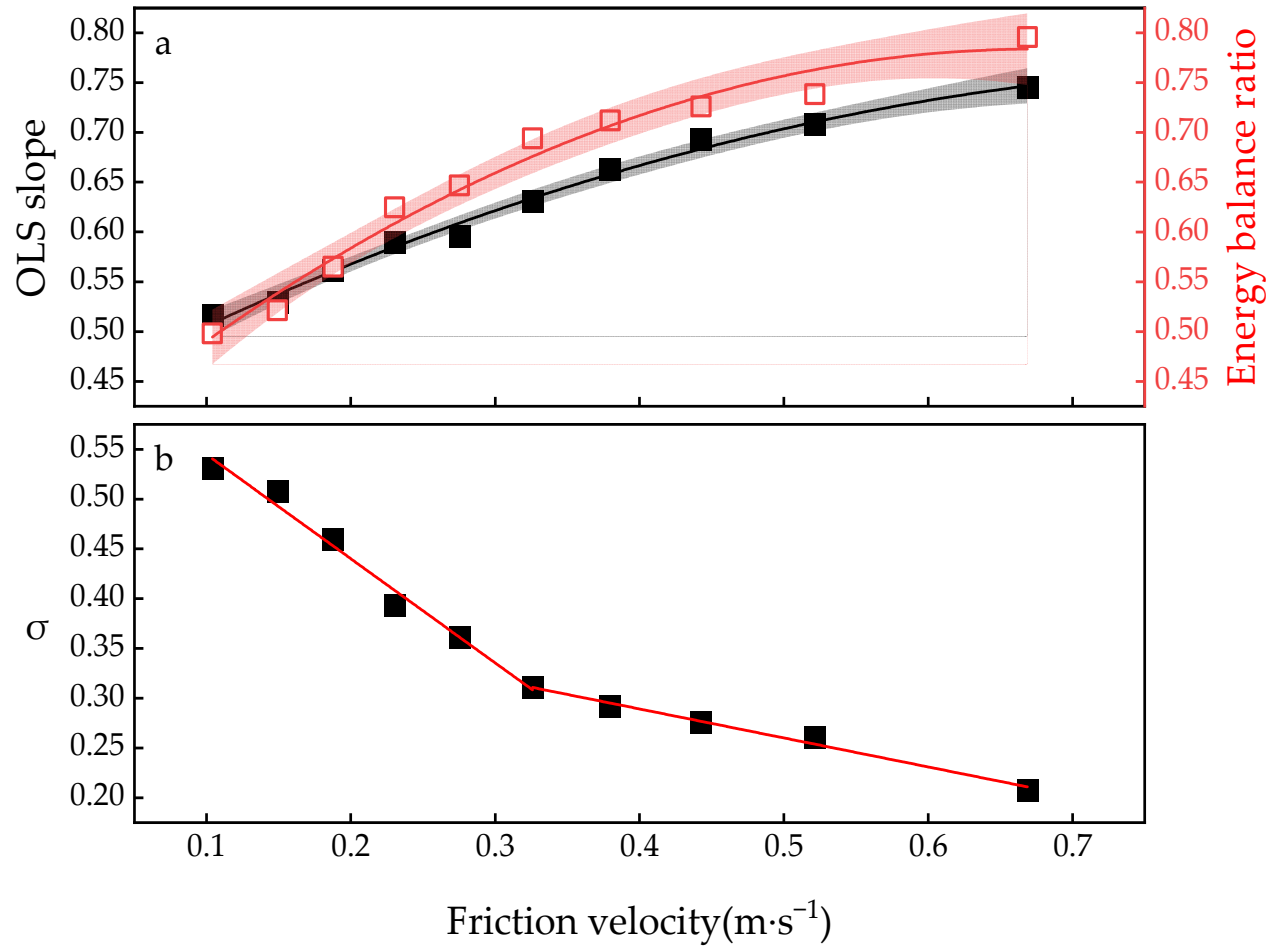

Figure 7. Effect of $\mathbf{u}^{*}$ on the (a) EBC and (b) $\sigma$ during daytime. The red boxes and black squares in (a) are the median values of EBR and OLSs per decile, and the red and black solid lines indicate their best-fit relationships with $\mathrm{u}^{*}$, which are defined as $\mathrm{EBR}=-0.891\left(\mathrm{u}^{*}\right)^{2}+1.201\left(\mathrm{u}^{*}\right)+0.379, \mathrm{R}^{2}=0.98$; OLSs $=-0.420\left(\mathrm{u}^{*}\right)^{2}+0.747\left(\mathrm{u}^{*}\right)+0.435, \mathrm{R}^{2}=0.99$, respectively. In $(\mathbf{b}), \sigma$ is expressed as the ratio of Res to available energy (that is, $\sigma=\operatorname{Res} /(\operatorname{Rn}-\mathrm{G}-\mathrm{S})$ ), and the following best relationships were obtained by linear fitting: $\sigma=-1.046 \mathrm{u}^{*}+0.649\left(\mathrm{u}^{*}<0.32 \mathrm{~m} \cdot \mathrm{s}^{-1}\right), \sigma=-0.291 \mathrm{u}^{*}+0.406\left(\mathrm{u}^{*}>0.32 \mathrm{~m} \cdot \mathrm{s}^{-1}\right)$, $\mathrm{R}^{2}=0.99$.

As shown in Figure $7 \mathrm{~b}$, this situation is consistent with expectations. As $\mathrm{u}^{*}$ increased, EBC improved, and energy residues in the forest decreased accordingly. In addition, the change of $\sigma$ appeared a turning point at $0.32 \mathrm{~m} \cdot \mathrm{s}^{-1}$, and the trend kept synchronized with EBC. When $u^{*}$ reached its maximum value, $20 \%$ of the energy remained.

\subsubsection{Relationship between EBC and Atmospheric Stability}

The relationship between EBC and $\zeta$ was evaluated using the same method (Figure 8). The figure shows that the variations in EBR and OLSs are consistent. The degree of EBC increases slowly from the very unstable conditions to near-unstable conditions (0.5 0.65), and the median EBR and OLSs approached the peak (0.7 or 0.68$)$ under near-neutral conditions. On the other hand, the EBC values decreased steeply in the neutral and stable cases, producing minimum values under very stable conditions. Due to turbulence intensity being closely related to atmospheric stability, $\mathrm{u}^{*}$ determines the magnitude of atmospheric stability, and the correlation between them was analyzed. It can be seen from the figure that $\mathrm{u}^{*}$ was extremely low in stable and very unstable conditions and increased rapidly in unstable and near-neutral conditions. Overall, the EBC is best in the case of a larger $\mathrm{u}^{*}$ and unstable atmospheric conditions.

Table 1 shows the degree of EBC for each atmospheric condition during the different seasons. According to Table 1, the OLSs and EBR varied consistently for different $\mathrm{u}^{*}$ values and atmospheric stabilization. The EBC increased with $u^{*}$ in all seasons, especially in the rainy season, with EBC values above 0.60 occurring at $\mathrm{u}^{*}>0.2 \mathrm{~m} \cdot \mathrm{s}^{-1}$, but in the hot-dry and foggy-cool seasons at $\mathrm{u}^{*}>0.32 \mathrm{~m} \cdot \mathrm{s}^{-1}$. The EBR was higher in unstable atmospheres than in stable atmospheres, with the best results occurring in the near-neutral case. The closure is significantly higher in the rainy season than in the other seasons (here, EBR appears to 
be a special case, which may be influenced by turbulence and had more fluctuations in the half-hourly EBR values). The remaining variations are consistent with those depicted in the above subsections. The differences observed during the study period were related to the different rainfall volumes during these seasons.

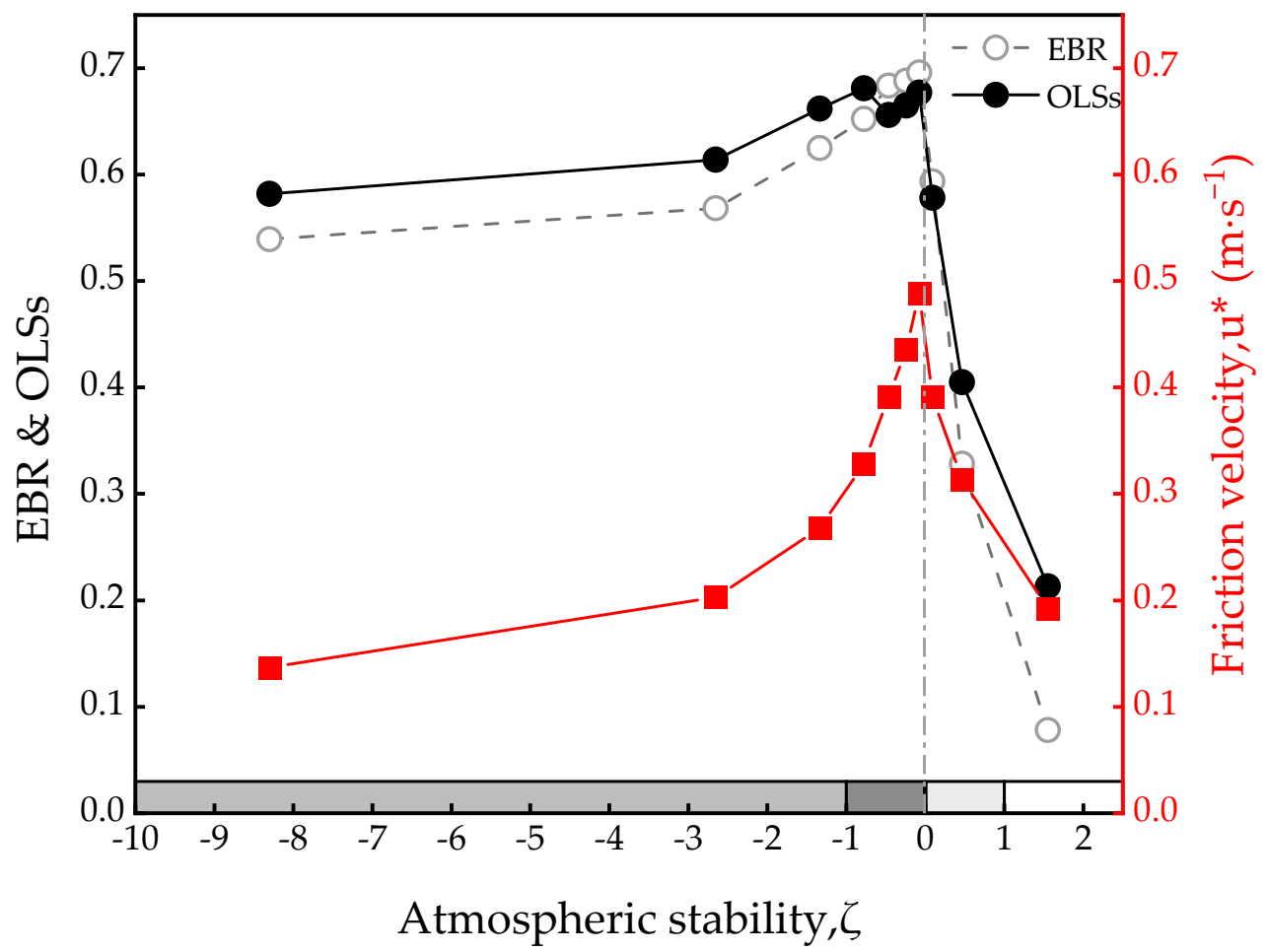

Figure 8. Effect of the atmospheric stability $\zeta$ on the surface energy closure fraction (including EBR and OLSs) and friction velocity $\mathrm{u}^{*}$ during the daytime. The circles indicate the EBR values, the dots indicate the slope of the linear regression, and the squares indicate $u^{*}$. The different colors at the bottom indicate the five categories of atmospheric stability, with gray being very unstable, dark gray being unstable, black being neutral (the range is too small to be easily seen in the figure), ash gray being stable, and white being very stable.

Table 1. Surface energy closure fraction (including EBR and OLSs) in response to friction velocity $\mathrm{u}^{*}$ and atmospheric stability $\zeta$ for each season during the study period.

\begin{tabular}{cccccccc}
\hline \multirow{2}{*}{} & \multirow{2}{*}{$\mathbf{n}$} & \multicolumn{2}{c}{ Hot-Dry Season } & \multicolumn{2}{c}{ Rainy Season } & \multicolumn{2}{c}{ Foggy-Cool Season } \\
\cline { 3 - 7 } & & OLSs & EBR & OLSs & EBR & OLSs & EBR \\
\hline $\mathrm{u}^{*}<0.2$ & 4277 & $0.439 \pm 0.012$ & 0.365 & $0.565 \pm 0.010$ & 0.474 & $0.429 \pm 0.008$ & 0.350 \\
$0.2<\mathrm{u}^{*}<0.32$ & 3876 & $0.509 \pm 0.016$ & 0.465 & $0.638 \pm 0.009$ & 0.675 & $0.498 \pm 0.007$ & 0.506 \\
$\mathrm{u}^{*}>0.32$ & 6173 & $0.627 \pm 0.009$ & 0.641 & $0.742 \pm 0.007$ & 0.773 & $0.607 \pm 0.008$ & 0.626 \\
$\zeta<-1$ & 4313 & $0.607 \pm 0.01$ & 0.553 & $0.698 \pm 0.007$ & 0.681 & $0.549 \pm 0.006$ & 0.515 \\
$-1<\zeta<-0.01$ & 5598 & $0.607 \pm 0.009$ & 0.584 & $0.729 \pm 0.007$ & 0.772 & $0.580 \pm 0.007$ & 0.570 \\
$-0.01<\zeta<0.01$ & 228 & $0.517 \pm 0.077$ & 0.649 & $0.674 \pm 0.039$ & 0.575 & $0.621 \pm 0.007$ & 0.788 \\
$0.01<\zeta<1$ & 3055 & $0.516 \pm 0.023$ & 0.515 & $0.560 \pm 0.018$ & 0.461 & $0.387 \pm 0.018$ & 0.314 \\
$\zeta>1$ & 1132 & $0.134 \pm 0.058$ & 0.040 & $0.280 \pm 0.037$ & 0.091 & $0.165 \pm 0.027$ & 0.047 \\
\hline
\end{tabular}

\subsection{Effects of Energy Non-Closure on Estimating Plant Evapotranspiration}

The Bowen ratio $(\beta)$ represents the exchange of hydrothermal energy between the atmosphere and the underlying surface, which determines the distribution of energy in the ecosystem and is expressed as sensible heat divided by latent heat. The correlation between the $\beta$ and $u^{*}$ is shown in Figure $9 a$, and the results are surprising. When $u^{*}<0.32 \mathrm{~m} \cdot \mathrm{s}^{-1}, \beta$ decreased rapidly as $u^{*}$ values gradually increased, reaching the lowest value at $0.32 \mathrm{~m} \cdot \mathrm{s}^{-1}$. 
The downward trend was linear, the best linear equation $\beta=-0.49 u^{*}+0.53$ was obtained by fitting, and the coefficient of determination $\mathrm{R}^{2}$ reached 0.95 , followed by a gentle rebound at $\mathrm{u}^{*}>0.32 \mathrm{~m} \cdot \mathrm{s}^{-1}$. The above analysis proves that a very small $\mathrm{u}^{*}$ affects the EBC, with the turbulent flux mainly being affected. We wished to observe the response of sensible and latent heat to $\mathrm{u}^{*}$ in this region and determine which factors played a major role in causing such a pattern. Therefore, we analyzed the variation in LE and Hs at different $u^{*}$ values (Figure $9 b$ ). It was found that $u^{*}$ had a great influence on LE, and the $\mathrm{LE}$ increased $255.55 \mathrm{~W} \cdot \mathrm{m}^{-2}$ from the minimum to the maximum of $\mathrm{u}^{*}$, while the change of Hs was small, and the range was only from 22.35 to $95.82 \mathrm{~W} \cdot \mathrm{m}^{-2}$. At $\mathrm{u}^{*}<0.32 \mathrm{~m} \cdot \mathrm{s}^{-1}$, LE made a significant contribution to $\beta$. After that, the increase rates of LE and Hs became slow, and $\beta$ remained almost constant.

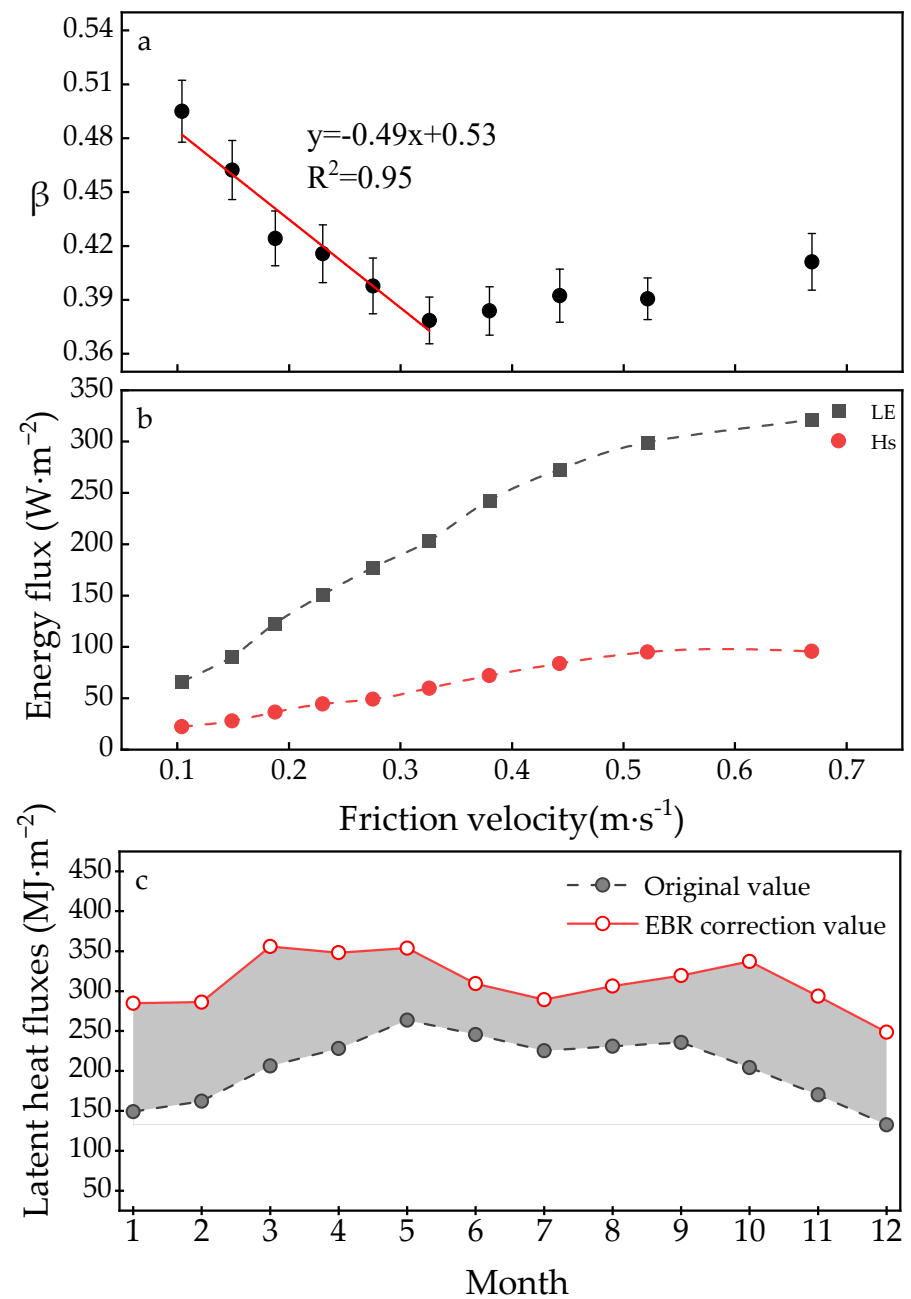

Figure 9. (a) Bowen ratio, $\beta$ and (b) turbulent flux, LE and Hs as a function of $u^{*}$, and (c) monthly variation of LE correction values. Where the straight line in (a) is the best-fit line of $\beta$ at $\mathrm{u}^{*}<0.32 \mathrm{~m} \cdot \mathrm{s}^{-1}$, satisfying the equation $\beta=-0.49 u^{*}+0.53, R^{2}=0.95$, and (c) the shaded part is the underestimated part of LE.

Turbulent fluxes are underestimated when $\mathrm{u}^{*}$ is too small, which affects the EBC. To what extent is the turbulent flux underestimated in the tropical calm zone? What effect can be produced in terms of the energy imbalance on surface-atmosphere water and heat exchange? To answer these questions, we corrected the turbulent fluxes using $\beta$ and the EBR. Hs and LE were corrected by assuming a constant $\beta$, and the energy closure deficits were assigned according to the $\beta$ to back-calibrate the Hs and LE values, observing the effect of energy non-closure on the estimated evapotranspiration. The low valuation of LE is illustrated in Figure 9c (Hs was less underestimated and is not shown in the picture). 
Several characteristics can be observed in the results. First, the monthly cumulative values of the original monitoring data showed the lowest value of $132 \mathrm{MJ} \cdot \mathrm{m}^{-2}$ in the foggy-cool season, the temperature rose, and moisture evaporation increased in the hot-dry season, and the rainfall replenished the forest moisture during the rainy season, so the LE remained at a high level (varied from 200 to $260 \mathrm{MJ} \cdot \mathrm{m}^{-2}$ ). Second, the corrected LE values showed different monthly variations, with the maximum and minimum values occurring in the hot-dry season and the foggy-cool season. It is worth noting that a trough value occurred in the rainy season and returned to normal at the end of the rainy season. Finally, it can be seen that more LE values were underestimated during the foggy-cool and hot-dry seasons, both exceeding $100 \mathrm{MJ} \cdot \mathrm{m}^{-2}$, and only a small underestimation existed in the rainy season $\left(63.71-90.28 \mathrm{MJ} \cdot \mathrm{m}^{-2}\right)$.

\subsection{EBC at Different Temporal Scales}

Figure 10 shows the EBC at different temporal scales, based on half-hourly data to calculate hourly, daily, weekly, and monthly averages and obtain data for longer temporal scales. This analysis used OLSs to represent EBC, and the directly collected half-hourly data are shown in Figure 5a, and turbulent fluxes are clearly underestimated. Based on Figure 10, the linear regression slopes forced past the origin on hourly, daily, weekly, and monthly scales are $0.639,0.646,0.650$, and 0.649 , respectively. Results on longer time scales contradict expectations; EBC does not improve significantly and barely changes.

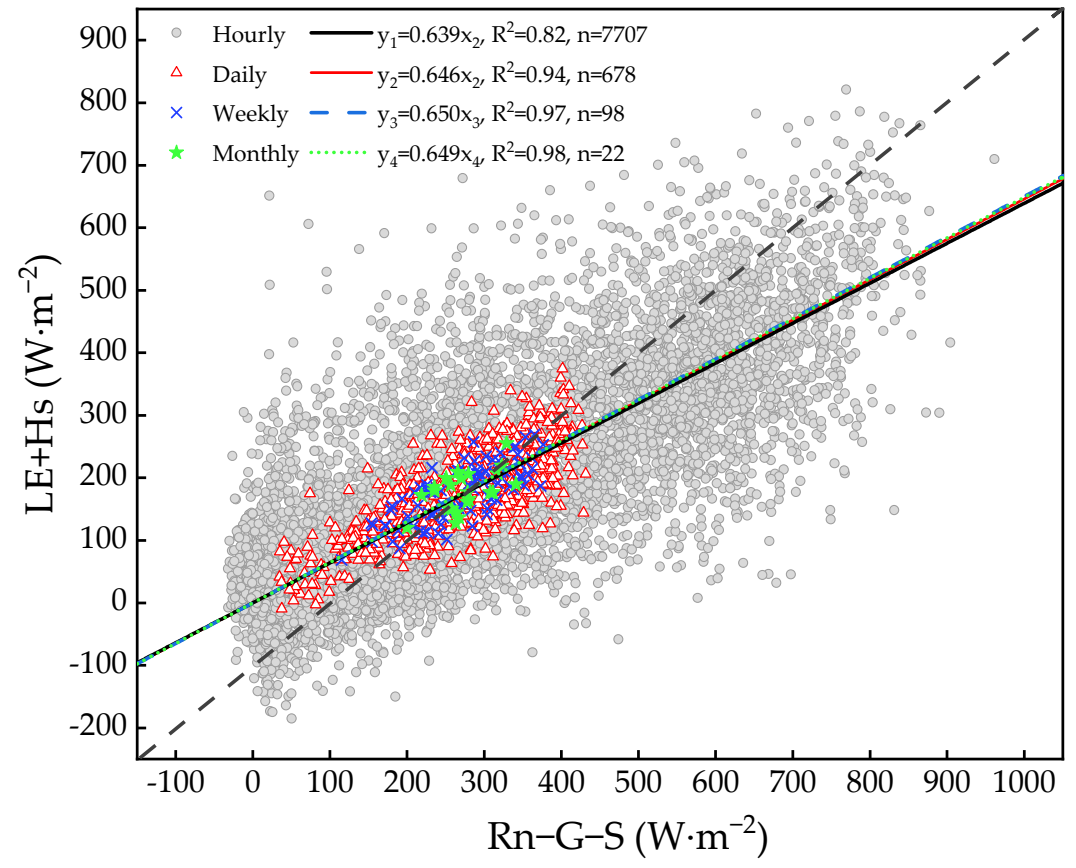

Figure 10. Scatter plots of the turbulent flux versus available energy (hourly, daily, weekly, and monthly). The gray dots are hourly data points, and the black straight line is its fitted line; the red triangles are daily data, and the linear fit result is represented as red straight lines; the dark blue forks indicate weekly data, the linear fit result as blue dashed lines, the green pentagrams are monthly data, and the fitted straight line is represented by green dotted lines.

\section{Discussion}

Xishuangbanna is located on the tropical northern edge of Southeast Asia, where the Himalayan mountains play an important role in shaping the regional climate. In summer, warm and humid air from the Indian Ocean is cut off by the Himalaya mountains, leading to abundant rainfall in this area. In winter, they act as a barrier to prevent the cold air mass from the north, leading to high temperatures throughout the year [40]. The data in micrometeorological measurements also showed a specific climatic pattern in this region 
(Figure 2). The changes in solar radiation, temperature, and LAI were inseparable from rainfall regulation, which explained the important role of water in phenology, climate, and forest productivity. This had been confirmed in previous studies [15,41,42]. Solar radiation acts as an energy source for ecosystems and drives a range of biochemical reactions. However, the actual amount of radiation received by the surface is controlled by the moisture content in the air (clouds, fog, rainfall, and other phenomena that will reduce the transmissivity of solar radiation), which in turn affects the mass and energy exchange process between the surface and the atmosphere. EBC can reflect this relationship well [3].

This leads us to conjecture that moisture content and solar radiation are the main factors affecting EBC. Therefore, we observed the EBC in this region using the two methods and obtained the same results (Figures 5 and 6). Both indicate that the EBC in this period has an obvious seasonal pattern, coinciding with seasonal changes in moisture content. Higher EBC occurs in the rainy season, which was also verified in the studies of Michiles et al. and Wilson et al. [43,44]. The rainy season supplies adequate water, and litter decomposition replenishes the soil nutrients in the hot-dry season. Plants rapidly photosynthesize to increase productivity, and the LAI reaches high levels. A higher LAI provides greater homogeneity of the underlying surface and contributes to greater performance of the EC system.

It should be noted that one of the reasons for better closure during the rainy season is the variability of plant phenology in the study area. This result is consistent with the study of Campos et al. [15]. The above analysis reveals that in this region, the turbulent energy is mainly dominated by LE. (Figure $9 b, c$ ). In the growing season with suitable environmental conditions, vegetation coverage increases, stomatal opening, evaporation, and respiration strengthen. During this period, the atmospheric stability was almost unstable to near neutral (Figure $4 \mathrm{~d}$ ), the turbulent exchange was optimal, and the mass and energy exchange between the underlying surface and atmosphere were relatively strong, causing greater LE transport, and the EBC was the highest (Figure 8). In the hot-dry season, the radiation energy reaches the ground, the underlying surface temperature is high, and the evapotranspiration is higher than that in the foggy-cool season. The LE is the main factor influencing EBC, so EBC appears to have higher values in the hot-dry season than in the foggy-cool season. In addition, $\mathrm{u}^{*}$ is small in the foggy-cool season, and $\zeta$ is mostly very unstable. It can be seen from Figure 8 that these factors also lead to low EBC in the foggy-cool season.

In this study, the importance of seasonal changes in rainfall, solar radiation, and LAI for EBC was demonstrated in Xishuangbanna, and it should be noted that similar results have been obtained in some regions that also suffer water stress [4]. In addition, environmental conditions play an important role in EBC. When environmental conditions are suitable, the plants' physiological and metabolic activities become active, stomatal conductance increases, photosynthetic capacity, and transpiration rate are enhanced, mass and energy exchanges become intense, convective frequency increases, and EBC improves.

Environmental factors such as climate and topography vary among forest ecosystems, making the EBC different in contrasting regions. Takanashi et al. reported water and heat exchange in a Malaysian tropical rainforest, where an EBC of 78\% was observed after considering the heat storage, and EBC reached $80 \%$ at high $\mathrm{u}^{*}$ conditions [45]. The EBC of tropical broadleaf evergreen forests in Indonesia reached 0.74 [46]. Tropical deciduous forests in northern Thailand are close to the study area in latitude and longitude and have similar climate types, with a relatively small EBC of 0.68 [47]. Compared with these regions, the energy non-closure in the Xishuangbanna tropical seasonal rainforest is higher than that in other forests, with OLSs and EBRs less than 0.68. In addition, EBC can be improved by including heat storage terms, which are usually neglected in the analysis [48]. In this study, we exclude the reasons that heat storage leads to energy non-closure. Moreover, the contribution of heat storage to EBC is very small even if they are taken into account, contradicting McCaughey's opinion [28]. This indicates that EBC is influenced by factors other than rainfall and heat storage. 
Previous studies have reported the correlation between EBC and turbulence intensity [49-51]. In the Malaysian tropical rainforest, the EBC corresponding to the minimum and maximum $\mathrm{u}^{*}$ are 0.65 and 0.83 , respectively [45]. The EBC rapidly improves with $\mathrm{u}^{*}$ in Finland boreal forest, and EBR values reach over $90 \%$ when $\mathrm{u}^{*}$ is more than $0.8 \mathrm{~m} \cdot \mathrm{s}^{-1}$ [36]. This phenomenon is also present in the tropical seasonal rainforests of Xishuangbanna. The region is known as a calm zone, with the average wind velocity in the observation year at $0.9 \mathrm{~m} \cdot \mathrm{s}^{-1}$. Because $\mathrm{u}^{*}$ determines the degree of atmospheric stability, we explored the interrelationship among $\mathrm{u}^{*}, \zeta$, and EBC and their contribution to EBC (Figures 7a and 8).

We found that OLSs, EBR, and $\mathrm{u}^{*}$ showed suitable positive correlations with each other, and the best EBC was obtained at larger $\mathrm{u}^{*}$ values. That is, a low $\mathrm{u}^{*}$ is the main factor leading to energy non-closure. The response of the EBC to each $\zeta$ category is shown in Figure 8. The most significant difference was the transition from the near-neutral atmospheric state (maximum) to the steady-state (rapid drop in EBC values). In contrast, during the transition from the very unsteady state to the near-neutral state, only a slow boost was observed in the EBC. The relationship between these parameters and EBC has been considered in several studies, and their results agree with ours $[27,33,52,53]$. The EBC is most infertile in neutral and steady atmospheric states because $u^{*}$ decreases greatly in this period, and low $\mathrm{u}^{*}$ conditions usually indicate poorly developed turbulence; in this case, the EC system was shown to underestimate the true atmospheric exchange, leading to an imbalance in the energy budget [54]. In addition, advective transport under steady conditions may also contribute to energy imbalance [11]. Therefore, it is reasonable to assume that the best EBC is observed under unstable atmospheric conditions.

On the other hand, to investigate the EBC problem further, we carried out our analysis using different temporal scales and found that the energy balance non-closure bears a connection with a complicated underlying surface. The EBC of the homogeneous surface is greater than that of the heterogeneous surface. The vegetation coverage becomes more uniform, increasing the homogeneity of the underlying surface and improving the performance of the EC system [55]; therefore, the EBC is optimal in the rainy season. We initially thought that the underlying surface heterogeneity was one of the main reasons for the lack of EBC because the heterogeneous surface will come into being larger temporal scale eddies than conventional EC methods (30 min), implying that some of the low-frequency turbulence is missed [56,57]. Extending the time scales and outputting data at daily, monthly intervals can effectively reduce low-frequency losses and improve EBC [16,58]. However, by analyzing the EBC at different time scales, it was found that extending the time scale had little effect on the EBC (Figure 10), implying that the region conforms to the ideal state of the Ogive equation (Case 1). The 30 min covariance is a reliable estimate of the turbulent flux, and high- and low-frequency turbulence can be covered in this interval [59].

We also found a steep drop in $\beta$ at $u^{*}<0.32 \mathrm{~m} / \mathrm{s}$. The value of $\beta$ represents the hydrothermal energy exchange between the atmosphere and ecosystems, and the magnitude of $\beta$ determines the distribution of energy in the ecosystem, which is expressed as sensible heat divided by latent heat. The EBC is also directly related to the assessment of LE and Hs [33]. To explore whether the change in LE or Hs caused this result and the magnitude of their contribution to EBC, we analyzed the relationship between turbulent flux and $\mathrm{u}^{*}$ (Figure 9b). We found that the LE can be greatly enhanced when the turbulent exchange is sufficient, as much as three times higher than the Hs, and the vast majority of the energy is used for evapotranspiration.

What exactly is the turbulent flux in this unique region, and if topography and climate effects cause the fluxes to be underestimated? With the help of the Bowen ratio, the turbulent flux was corrected by EBC (Figure 9c). The results show that the underestimation of fluxes is larger in the foggy-cool and hot-dry seasons, and the underestimated part was relatively small during the rainy season. We predict that the result is related to the turbulence intensity. A clue can be obtained from the annual variation of $u^{*}$ (Figure $4 b$ ), where the average level of $\mathrm{u}^{*}$ is below $0.3 \mathrm{~m} / \mathrm{s}$ during the foggy-cool season. This makes the turbulent exchange weak, and the EC system cannot perfectly capture the hydrothermal information 
released from the underlying surface, so the LE and Hs are heavily underestimated during this period. We also found that the turbulent flux increased from the beginning to the end of the hot-dry season, regardless of the calibration value or the original monitored value, and the maximum value appeared at the end of the hot-dry season. It was expected that the LE should peak during the rainy season, but this was not the case. Instead, the turbulent flux decreased in the early phase of the rainy season and then rebounded in the later part. Variations in cloudiness and albedo lead to differences in net radiation over the seasons; therefore, the available energy for turbulent fluxes also differed.

Combined with the Penman-Monteith formula [60], this phenomenon is mainly attributed to meteorological factors, especially VPD and Rn. Heat (radiation and temperature) and moisture (SWC and VPD) factors are the key factors controlling exerting the water-heat exchange between the ground and air [61]. Rn has a direct influence on LE, which is a type of physical control. Because $\mathrm{Rn}$ is the driving factor for water vapor transport, $\mathrm{Rn}$ is larger; thus, more energy is allocated to the ecosystem and will have a stronger impact on LE [62]. The VPD also has a strong influence on LE. It exerts biological control and indirect effects by changing the stomatal conductance and affecting ecosystem respiration, which in turn causes changes in energy exchange processes [63]. In the hot-dry season, there is less cloud cover, the sunshine duration is longer, and sufficient light can be obtained, $\mathrm{Rn}$ reaches the maximum value, and the energy obtained from the underlying surface increases; thus, transpiration of plants and evaporation of water are enhanced. Warmer temperatures allow the air to hold more water molecules, but the season is typically dry with little rainfall, at which time the VPD appears to peak (Figure 2d). Therefore, LE in the hot-dry season was higher than in other seasons. A large number of rainfall events occur during the rainy season, the moisture in the air and soil is replenished, and the actual water vapor pressure increases. However, rainfall occurs mostly in the late afternoon when the solar altitude angle is large. The shielding effect of clouds and water vapor reduces the amount of solar radiation available on the underlying surface, leading to a reduction in turbulent fluxes during the rainy season.

\section{Conclusions}

This study investigates the surface EBC of tropical seasonal rainforests in Xishuangbanna, the environmental influences, and the effect of energy non-closure on plant evapotranspiration estimates. The following discoveries were made. In the study area, there is a clear seasonal difference in EBC, with the rainy season being the best and the foggy-cool season the worst. This effect is inseparable from the local climate pattern and is especially closely related to the moisture content and solar radiation. The overall EBC was not satisfactory, and the non-closure in the study region was high compared to other tropical rainforests. We analyzed the inducing factors for this situation and ruled out the possibility that neglecting heat storage reduced $\mathrm{EBC}$, the heat storage cannot effectively improve EBC, and it was not the key to energy non-closure. The above results show that the wind velocity in the tropical calm zone is small, and EBC benefits from adequate turbulent exchange, with better EBC occurring at larger $u^{*}$, which can reach $80 \%$. However, it was also found that there was a limit to the effect of $u^{*}$ on EBC. Once $u^{*}$ reaches a certain value, there is little effect on EBC, and the closure no longer increases. In addition, the $30 \mathrm{~min}$ average used by the conventional eddy covariance method can effectively contain both high- and low-frequency flux data during the study period. Moreover, extending the time scales scarcely improves the EBC, implying that very large time scales can be excluded and that underlying surface heterogeneity is not the main reason for energy non-closure.

Our results also strongly suggest that energy non-closure can largely underestimate the LE when using the EC method to estimate evapotranspiration and that it is necessary to consider an energy imbalance correction. After correction, LE from tropical seasonal rainforest was significantly elevated with more underestimation in the foggy-cool and hot-dry seasons and less in the rainy season. The energy in this region is mainly used for evapotranspiration, with little change in Hs. However, it should be noted that our study 
only included one year of data for a single forest site, and the problem of energy non-closure has not been thoroughly explored. Therefore, more research is needed to improve the EBC in this region, covering a longer period of time, and more data from further experiments need to be analyzed.

Author Contributions: Methodology, Y.L.; Software, Y.J.; supervision, J.L.; validation, Y.L. and X.Z.; visualization, Y.J.; writing—original draft, Y.J.; writing—review \& editing, X.Z. All authors have read and agreed to the published version of the manuscript.

Funding: His research was funded by the National Natural Science Foundation of China (No. 41771099, 41861023), the E-Talent project of Hainan University (KYQD2R1968).

Institutional Review Board Statement: Not applicable.

Informed Consent Statement: Not applicable.

Data Availability Statement: Data sharing not applicable.

Acknowledgments: We sincerely thank the Xishuangbanna Station for Tropical Rain Forest Ecosystem Studies for providing the eddy covariance data used in this study.

Conflicts of Interest: The authors declare no conflict of interest.

\section{References}

1. Huenneke, L.F.; Anderson, J.P.; Remmenga, M.; Schlesinger, W.H. Desertification alters patterns of aboveground net primary production in Chihuahuan ecosystems. Glob. Chang. Biol. 2002, 8, 247-264. [CrossRef]

2. Baldocchi, D.D.; Hincks, B.B.; Meyers, T.P. Measuring biosphere-atmosphere exchanges of biologically related gases with micrometeorological methods. Ecology 1988, 69, 1331-1340. [CrossRef]

3. Nelli, N.R.; Temimi, M.; Fonseca, R.M.; Weston, M.J.; Thota, M.S.; Valappil, V.K.; Branch, O.; Wizemann, H.D.; Wulfmeyer, V.; Wehbe, Y. Micrometeorological measurements in an arid environment: Diurnal characteristics and surface energy balance closure. Atmos. Res. 2020, 234, 104745. [CrossRef]

4. Majozi, N.P.; Mannaerts, C.M.; Ramoelo, A.; Mathieu, R.; Nickless, A.; Verhoef, W. Analysing surface energy balance closure and partitioning over a semi-arid savanna FLUXNET site in Skukuza, Kruger National Park, South Africa. Hydrol. Earth Syst. Sci. 2017, 21, 3401-3415. [CrossRef]

5. $\quad$ Friedlingstein, P.; Cox, P.; Betts, R.; Bopp, L.; Bloh, W.V.; Brovkin, V.; Cadule, P.; Doney, S.; Eby, M.; Fung, I. Climate-Carbon Cycle Feedback Analysis: Results from the C4MIP Model Intercomparison. J. Clim. 2006, 19, 3337-3353. [CrossRef]

6. Richardson, A.D.; Mahecha, M.D.; Falge, E.; Kattge, J.; Moffat, A.M.; Papale, D.; Reichstein, M.; Stauch, V.J.; Braswell, B.H.; Churkina, G.; et al. Statistical properties of random $\mathrm{CO}_{2}$ flux measurement uncertainty inferred from model residuals. Agric. For. Meteorol. 2007, 148, 38-50. [CrossRef]

7. Oncley, S.P.; Foken, T.; Vogt, R.; Kohsiek, W.; DeBruin, H.A.R.; Bernhofer, C.; Christen, A.; Gorsel, E.V.; Grantz, D.; Feigenwinter, C.; et al. The Energy Balance Experiment EBEX-2000. Part I: Overview and energy balance. Bound-Lay. Meteorol. 2007, 123, 1-28. [CrossRef]

8. Foken, T.; Oncley, S. Workshop on Instrumental and Methodical Problems of Land Surface Flux Measurements. Bull. Am. Meteorol. Soc. 1995, 76, 1191-1224. [CrossRef]

9. Thomas, F. The energy balance closure problem: An overview. Ecol. Appl. 2008, 18, 1351-1367.

10. Stoy, P.C.; Mauder, M.; Foken, T.; Marcolla, B.; Boegh, E.; Ibrom, A.; Arain, M.A.; Arneth, A.; Aurela, M.; Bernhofer, C.; et al. A data-driven analysis of energy balance closure across FLUXNET research sites: The role of landscape scale heterogeneity. Agric. For. Meteorol. 2013, 171-172, 137-152. [CrossRef]

11. Leuning, R.; Gorsel, E.V.; Massman, W.J.; Isaac, P.R. Reflections on the surface energy imbalance problem. Agric. For. Meteorol. 2012, 156, 65-74. [CrossRef]

12. Meyers, T.P.; Hollinger, S.E. An assessment of storage terms in the surface energy balance of maize and soybean. Agric. For. Meteorol. 2004, 125, 105-115. [CrossRef]

13. Anderson, R.G.; Wang, D. Energy budget closure observed in paired Eddy Covariance towers with increased and continuous daily turbulence. Agric. For. Meteorol. 2014, 184, 204-209. [CrossRef]

14. Tanaka, H.; Hiyama, T.; Kobayashi, N.; Yabuki, H.; Ishii, Y.; Desyatkin, R.V.; Maximov, T.C.; Ohta, T. Energy balance and its closure over a young larch forest in eastern Siberia. Agric. For. Meteorol. 2008, 148, 1954-1967. [CrossRef]

15. Campos, S.; Mendes, K.R.; da Silva, L.L.; Mutti, P.R.; Medeiros, S.S.; Amorim, L.B.; dos Santos, C.A.C.; Perez-Marin, A.M.; Ramos, T.M.; Marques, T.V.; et al. Closure and partitioning of the energy balance in a preserved area of a Brazilian seasonally dry tropical forest. Agric. For. Meteorol. 2019, 271, 398-412. [CrossRef]

16. Grachev, A.A.; Fairall, C.W.; Blomquist, B.W.; Fernando, H.J.S.; Leo, L.S.; OtÃ rola-Bustos, S.F.; Wilczak, J.M.; McCaffrey, K.L. On the surface energy balance closure at different temporal scales. Agric. For. Meteorol. 2020, 281, 107823. [CrossRef] 
17. Zhang, Y.P.; Sha, L.Q.; Yu, G.R.; Song, Q.H.; Tang, J.W.; Yang, X.D.; Wang, Y.S.; Zheng, Z.; Zhao, S.J.; Yang, Z.; et al. Annual variation of carbon flux and impact factors in the tropical seasonal rain forest of Xishuangbanna, SW China. Sci. China Earth Sci. 2006, 49, 150-162. [CrossRef]

18. Liu, W.J.; Zhang, Y.P.; Li, H.M.; Liu, Y.H. Fog drip and its relation to groundwater in the tropical seasonal rain forest of Xishuangbanna, Southwest China: A preliminary study. Water Res. 2005, 39, 787-794. [CrossRef]

19. Tan, Z.H.; Zhang, Y.P.; Song, Q.H.; Yu, G.R.; Liang, N.S. Leaf shedding as an adaptive strategy for water deficit: A case study in Xishuangbanna's rainforest. J. Yunnan Univ. -Nat. Sci. Ed. 2014, 36, 273-280.

20. Zhang, R.; Dong, T.F.; Deng, X.B.; Liu, J.Y. Vegetation numerical classification and ordination of a 20-hectare tropical forest plot in Xishuangbanna, Southwest Yunnan. Chin. J. Ecol. 2018, 37, 347-352.

21. Liu, W.J.; Zhang, Y.P.; Li, H.M.; Liu, Y.H. Fog characteristics in a tropical seasonal rain forest in Xishuangbanna, Southwest China. Chin. J. Plant Ecol. 2004, 28, 264-270.

22. Aubinet, M.; Grelle, A.; Ibrom, A.; Rannik, Ü.; Moncrieff, J.; Foken, T.; Kowalski, A.S.; Martin, P.H.; Berbigier, P.; Bernhofer, C.; et al. Estimates of the Annual Net Carbon and Water Exchange of Forests: The EUROFLUX Methodology. Adv. Ecol. Res. 1999, 30, 113-175.

23. Falge, E.; Baldocchi, D.; Olson, R.; Anthoni, P.; Aubinet, M.; Bernhofer, C.; Burba, G.; Ceulemans, R.; Clement, R.; Dolman, H.; et al. Gap filling strategies for long term energy flux data sets. Agric. For. Meteorol. 2001, 107, 71-77. [CrossRef]

24. Falge, E.; Baldocchi, D.; Olson, R.; Anthoni, P.; Aubinet, M.; Bernhofer, C.; Burba, G.; Ceulemans, R.; Clement, R.; Dolman, H.; et al. Gap filling strategies for defensible annual sums of net ecosystem exchange. Agric. For. Meteorol. 2001, 107, 43-69. [CrossRef]

25. Tajchman, S.J. Comments on Measuring Turbulent Exchange Within and Above Forest Canopy. Bull. Am. Meteorol. Soc. 1981, 62, 1550-1559. [CrossRef]

26. Sun, C.; Jiang, H.; Chen, J.; Liu, Y.L.; Niu, X.D.; Chen, X.F.; Fang, C.Y. Energy flux and balance analysis of Phyllostachys edulis forest ecosystem in subtropical China. Acta Ecol. Sin. 2015, 35, 4128-4136.

27. Dare-Idowu, O.; Brut, A.; Cuxart, J.; Tallec, T.; Rivalland, V.; Zawilski, B.; Ceschia, E.; Jarlan, L. Surface energy balance and flux partitioning of annual crops in southwestern France. Agric. For. Meteorol. 2021, 308-309, 108529. [CrossRef]

28. McCaughey, J.H. Energy balance storage terms in a mature mixed forest at Petawawa, Ontario-A case study. Bound-Lay. Meteorol. 1985, 31, 89-101. [CrossRef]

29. Blanken, P.D.; Black, T.A.; Yang, P.C.; Neumann, H.H.; Nesic, Z.; Staebler, R.; den Hartog, G.; Novak, M.D.; Lee, X. Energy balance and canopy conductance of a boreal aspen forest: Partitioning overstory and understory components. J. Geophys. Res. 1997, 102, 28915-28927. [CrossRef]

30. Oliphant, A.J.; Grimmond, C.S.B.; Zutter, H.N.; Schmid, H.P.; Su, H.-B.; Scott, S.L.; Offerle, B.; Randolph, J.C.; Ehman, J. Heat storage and energy balance fluxes for a temperate deciduous forest. Agric. For. Meteorol. 2004, 126, 185-201. [CrossRef]

31. Masseroni, D. Limitations and improvements of the energy balance closure with reference to experimental data measured over a maize field. Atmósfera 2014, 27, 335-352. [CrossRef]

32. Li, Z.Q.; Yu, G.R.; Wen, X.F.; Zhang, L.M.; Ren, C.Y.; Fu, Y.L. Energy balance closure at ChinaFLUX sites. Sci. China Earth Sci. 2005, 48, 51-62.

33. McGloin, R.; Šigut, L.; Havránková, K.; Dušek, J.; Pavelka, M.; Sedlák, P. Energy balance closure at a variety of ecosystems in Central Europe with contrasting topographies. Agric. For. Meteorol. 2018, 248, 418-431. [CrossRef]

34. Xiao, X. A Study on Characteristics of Turbulence and Turbulent Energy Transport with Surface Energy Unclosure over Native Grassland in the Semi-Arid Loess; PlateauLanzhou University: Gansu, China, 2011.

35. Foken, T. Micrometeorology; Springer Nature: Berlin/Heidelberg, Germany, 2016.

36. Sánchez, J.M.; Caselles, V.; Rubio, E.M. Analysis of the energy balance closure over a FLUXNET boreal forest in Finland. Hydrol. Earth Syst. Sci. 2010, 14, 1487-1497. [CrossRef]

37. Jarvis, P.G.; Leverenz, J.W. Productivity of Temperate, Deciduous and Evergreen Forests. In Physiological Plant Ecology $I V$; Lange, O.L., Nobel, P.S., Osmond, C.B., Ziegler, H., Eds.; Encyclopedia of Plant Physiology (New Series); Springer: Berlin/Heidelberg, Germany, 1983; Volume 12.

38. Holst, T.; Hauser, S.; Kirchgäßner, A.; Matzarakis, A.; Mayer, H.; Schindler, D. Measuring and modelling plant area index in beech stands. Int. J. Biometeorol. 2004, 48, 192-201. [CrossRef]

39. Goulden, M.L.; Munger, J.W.; Fan, S.M.; Daube, B.C.; Wofsy, S.C. Measurements of carbon sequestration by long-term eddy covariance: Methods and a critical evaluation of accuracy. Glob. Chang. Biol. 1996, 2, 169-182. [CrossRef]

40. Li, Z.H.; Zhang, Y.P.; Wang, S.S.; Yuan, G.F.; Yang, Y.; Cao, M. Evapotranspiration of a tropical rain forest in Xishuangbanna, southwest China. Hydrol. Process 2010, 24, 2405-2416. [CrossRef]

41. Tan, Z.H.; Zhang, Y.P.; Yu, G.R.; Sha, L.Q.; Tang, J.W.; Deng, X.B.; Song, Q.H. Carbon balance of a primary tropical seasonal rain forest. J. Geophys. Res. Atmos. 2010, 115, D00H26. [CrossRef]

42. Song, Q.H.; Lin, H.; Zhang, Y.P.; Tan, Z.H.; Zhao, J.F.; Zhao, J.B.; Zhang, Y.P.; Zhang, X.; Zhou, W.J.; Yu, L.; et al. The effect of drought stress on self-organisation in a seasonal tropical rainforest. Ecol. Modell. 2013, 265, 136-139. [CrossRef]

43. Michiles, A.A.dS.; Gielow, R. Above-ground thermal energy storage rates, trunk heat fluxes and surface energy balance in a central Amazonian rainforest. Agric. For. Meteorol. 2008, 148, 917-930. [CrossRef]

44. Wilson, K.; Goldstein, A.; Falge, E.; Aubinet, M.; Baldocchi, D.; Berbigier, P.; Bernhofer, C.; Ceulemans, R.; Dolman, H.; Field, C.; et al. Energy balance closure at FLUXNET sites. Agric. For. Meteorol. 2002, 113, 223-243. [CrossRef] 
45. Takanashi, S.; Kosugi, Y.; Ohkubo, S.; Matsuo, N.; Tani, M.; Nik, A.R. Water and heat fluxes above a lowland dipterocarp forest in Peninsular Malaysia. Hydrol. Process. 2010, 24, 472-480. [CrossRef]

46. Takashi, H.; Kitso, K.; Suwido, L.; Mitsuru, O. Evapotranspiration of tropical peat swamp forests. Glob. Chang. Biol. 2015, 21, 1914-1927.

47. Igarashi, Y.; Kumagai, T.; Yoshifuji, N.; Sato, T.; Tanaka, N.; Tanaka, K.; Suzuki, M.; Tantasirin, C. Environmental control of canopy stomatal conductance in a tropical deciduous forest in northern Thailand. Agric. For. Meteorol. 2015, 202, 1-10. [CrossRef]

48. Lindroth, A.; Mölder, M.; Lagergren, F. Heat storage in forest biomass improves energy balance closure. Biogeosciences 2010, 7, 301-313. [CrossRef]

49. Moffat, A.M.; Papale, D.; Reichstein, M.; Hollinger, D.Y.; Richardson, A.D.; Barr, A.G.; Beckstein, C.; Braswell, B.H.; Churkina, G.; Desai, A.R.; et al. Comprehensive comparison of gap-filling techniques for eddy covariance net carbon fluxes. Agric. For. Meteorol. 2007, 147, 209-232. [CrossRef]

50. Papale, D.; Reichstein, M.; Aubinet, M.; Canfora, E.; Bernhofer, C.; Kutsch, W.; Longdoz, B.; Rambal, S.; Valentini, R.; Vesala, T.; et al. Towards a standardized processing of Net Ecosystem Exchange measured with eddy covariance technique: Algorithms and uncertainty estimation. Biogeosciences 2006, 3, 571-583. [CrossRef]

51. Liu, S.; Bai, J.; Jia, Z.; Jia, L.; Zhou, H.; Lu, L. Estimation of evapotranspiration in the Mu Us Sandland of China. Hydrol. Earth Syst. Sci. 2010, 14, 573-584. [CrossRef]

52. Cui, W.H.; Chui, T.F.M. Temporal and spatial variations of energy balance closure across FLUXNET research sites. Agric. For. Meteorol. 2019, 271, 12-21. [CrossRef]

53. Barr, A.G.; Morgenstern, K.; Black, T.A.; McCaughey, J.H.; Nesic, Z. Surface energy balance closure by the eddy-covariance method above three boreal forest stands and implications for the measurement of the $\mathrm{CO}_{2}$ flux. Agric. For. Meteorol. 2006, 140, 322-337. [CrossRef]

54. Wolf, A.; Laca, E.A. Cospectral analysis of high frequency signal loss in eddy covariance measurements. Atmos. Chem. Phys. Discuss. 2007, 7, 13151-13173.

55. Althoff, T.; Menezes, R.; Carvalho, A.; Pinto, A.; Santiago, G.; Ometto, J.; Randow, C.; Sampaio, E. Climate change impacts on the sustainability of the firewood harvest and vegetation and soil carbon stocks in a tropical dry forest in Santa Teresinha Municipality, Northeast Brazil. For. Ecol. Manag. 2016, 360, 367-375. [CrossRef]

56. Foken, T.; Wimmer, F.; Mauder, M.; Thomas, C.; Liebethal, C. Some aspects of the energy balance closure problem. Atmos. Chem. Phys. 2006, 6, 4395-4402. [CrossRef]

57. Finnigan, J. The storage term in eddy flux calculations. Agric. For. Meteorol. 2004, 136, 108-113. [CrossRef]

58. Charuchittipa, D.; Babel, W.; Mauder, M.; Leps, J.P.; Foken, T. Extension of the averaging time in eddy-covariance measurements and its effect on the energy balance closure. Bound-Lay. Meteorol. 2014, 152, 303-327. [CrossRef]

59. Xiao, X.; Zuo, H.C.; Yang, Q.D.; Wang, S.J.; Wang, L.J.; Chen, J.W.; Chen, B.L.; Zhang, B.D. On the factors influencing surface-layer energy closure and their seasonal variability over the semi-arid Loess Plateau of Northwest China. Hydrol. Earth Syst. Sci. 2011, 16, 555-584. [CrossRef]

60. Zhang, H.; Xue, F.W. Flux Footprint Climatology Estimated by Three Analytical Models over a Subtropical Coniferous Plantation in Southeast China. J. Meteorol. Res. 2015, 29, 654-666. [CrossRef]

61. Wever, L.A.; Flanagan, L.B.; Carlson, P.J. Seasonal and interannual variation in evapotranspiration, energy balance and surface conductance in a northern temperate grassland. Agric. For. Meteorol. 2002, 112, 31-49. [CrossRef]

62. Xie, Y.; Wen, J.; Liu, R.; Wang, X.; Jia, D.Y. The Role of Solar Radiation and Water Vapor Pressure Deficit on Controlling Latent Heat Flux Density over the Alpine Wetland of the Source Region of the Yellow River. Plateau Meteor. 2018, 37, $614-625$.

63. Yagci, A.L.; Santanello, J.A.; Jones, J.W.; Barr, J. Estimating evaporative fraction from readily obtainable variables in mangrove forests of the Everglades, U.S.A. Int. J. Remote Sens. 2017, 38, 3981-4007. [CrossRef] 